\title{
Des-En-terrando achados: vistas sobre a África das diásporas
}

\author{
Marta Heloísa Leuba Salum*
}

\begin{abstract}
SALUM, M.H.L. Des-En-terrando achados: vistas sobre a África das diásporas. R. Museu Arq. Etn., São Paulo, n. 22: 195-218, 2012.
\end{abstract}

Resumo: Neste artigo apresentamos considerações sobre o uso da iconografia etnológica na abordagem da cultura material da África, a partir de pesquisas que temos realizado sobre as coleções museológicas do MAE/USP e Museu Paraense Emílio Goeldi-MPEG/MTCI. Tais considerações emergiram diante de certos objetos africanos relacionados a contextos negro-africanos no Brasil, mas concernem especialmente a estudos sobre formas e grafismos típicos das artes de sociedades de línguas bantu da África central, do final do século XIX à metade do século XX. Apontamos para a prudência com que essa iconografia, grafismos e formas devem ser tratados quando de sua aplicação como fonte de pesquisa.

Palavras-chaves: África: estudos de cultura material, Arte africana: estética bantu, Arte africana: iconografia, Arte africana: metalurgia, Brasil: coleções de etnologia africana, Imaginário África-Brasil.

\section{Introdução}

$\mathrm{N}$ este artigo apresentamos considerações sobre o uso da iconografia etnológica na abordagem da cultura material da África, a partir de pesquisas que temos realizado sobre as coleções museológicas do MAE/USP e Museu Paraense Emílio Goeldi-MPEG/MTCI. ${ }^{1}$

${ }^{*}$ ) Museu d Arqueologia e Etnologia da Universidade de São Paulo. Área de Etnologia Africana. <lisymhls@usp.br>

(1) A reprodução das imagens do acervo do Museu Paraense Emílio Goeldi neste artigo condiciona-se à autorização de direito de uso pelo MCTI/MPEG e foram fotografadas durante estágio realizado pela autora em 2009 e 2012 . Os estudos sobre o acervo do MPEG que vimos realizando desde o mestrado e o doutorado, desde sempre concernentes aos das coleções de etnologia africana do MAE/USP, integram hoje também o projeto de pesquisa do Núcleo de Apoio à Pesquisa Brasil África/PRP/USP fundado em 2011.
A arte e a cultura material da África são, de modo estereotipado, mais conhecidas através da escultura de estatuetas e máscaras de madeira. Entretanto, o segredo envolvido na metalurgia tradicional africana e os ritos de consagração nos processos de extração da matéria bruta, forja e fundição, e a importância dos ferreiros na hierarquia social, seu domínio de conhecimento sobre a natureza e o meio ambiente na sociedade antiga são fatores que poderiam iluminar com mais vigor o ciclo de vida de objetos africanos, e também os afro-brasileiros.

Esses fatores relacionados à metalurgia determinam um outro direcionamento, e também um outro olhar para os estudos de arte africana. Vale dizer o mesmo para o trabalho sobre as coleções de etnologia africana do MAE/USP. Referimo-nos às coleções de joias e "bronzes ogboni” constituintes do acervo reunidas por 
Marianno Carneiro da Cunha, desde em suas próprias anotações publicadas postumamente em Arte Afro-brasileira na História Geral da Arte de Walter Zanini (Carneiro da Cunha 1983) até artigos e relatórios de pesquisa de iniciação científica nesse assunto conduzida entre nós, de 2001 a 2004, por Ademir Ribeiro Jr. (2003 e 2008) e Renato Araujo da Silva (2006), assim como das coleções de ferramentas provenientes do Golfo da Guiné e dos candomblés baianos (Salum e Souza e Silva 2005-2006). Em termos cronológicos, a coleção de peças ogboni é, como se sabe, parte da produção dos iorubas. ${ }^{2}$ Através dessas peças podemos fazer referência a uma cronologia de pelo menos sete séculos em parte do território da atual Nigéria que poderia remontar ao apogeu da conhecida arte de Ifé. As joias, por sua vez, em maioria de latão, colocam-nos diante de imensa diversidade tecnológica e de fontes de inspiração de diferentes culturas da África. Exceto pelas duas ou três tábuas de alcorão existentes no acervo, é ali, entre as joias do acervo do MAE, que se pode garantir representada, entre outras formas de ideologia e manifestações de ordem e prestígio, a presença islâmica no continente.

Essas fontes de inspiração parecem estar presentes também em exemplares de armaria da coleção africana do Museu Paraense Emílio Goeldi-MPEG, em Belém, provenientes em

(2) Iorubá (pl. iorubás) é uma das poucas palavras dicionarizadas em português que expressa indivíduo, língua, povo - e é, assim, usada consensualmente. $\mathrm{Na}$ grafia do nome de povos de línguas bantu, seguimos normalmente os autores consultados, mas mantemos a prefixação ba-, usando o radical correspondente como adjetivo. Assim, veem-se no texto batshokwe e tshokwe, bakuba e kuba, bakongo e kongo ou, basonge e songye - neste caso, substituindo-se songe por songye que é mais utilizado hoje até mesmo como nome desse povo na literatura especializada. Mesmo sendo designações em línguas estrangeiras, elas vão sem o emprego do itálico no corpo do texto como seria de praxe, exceto no uso de bantu, mas o itálico não deixa de se aplicar na grafia dos nomes vernaculares de objetos e desenhos, como ibol, por exemplo. Também mantemos a grafia internacional bantu e nkisi, apesar de haver os correspondentes em português banto e inquice, e aportuguesamos palavras como botiô, em vez de usar as formas correntes na literatura em francês e inglês, bocio, boccio, bochio ou botchio. grande parte do Congo (ex-Zaire), cuja decoração poderia refletir a presença dos mercadores árabes que se deu na África central antes da introdução dos belgas na região.

Vê-se em tudo isso uma amostra das intensas relações e trocas existentes entre instituições e formas artísticas em um território extensivo, que ultrapassou divisas étnicas desde mesmo antes da partilha da África, e que se representam em objetos e, mesmo, em inscrições gráficas nesses objetos, também feitas em vários outros suportes artefatuais. Não podemos perder de vista também a identificação de muitas formas materiais feitas no Brasil com as da África, que vêm sendo discutidas desde os primeiros estudos sobre o Negro no Brasil para além dos estudos de cultura material.

Desse modo, nossas considerações se dão também face a certos objetos africanos relacionados a contextos negro-africanos no Brasil, mesmo que elas aqui se atenham no campo dos estudos sobre artes de sociedades de línguas bantu da África central, do final do século XIX à metade do século $\mathrm{XX}$, e que nossa abordagem se situe mais precisamente em uma linha de pesquisa relativa aos significados e potencialidade de artefatos e cultura material através de estudos de coleções em museus.

Motivou o que aqui se apresenta um objeto que nos foi apresentado como uma "lança quilombola", encontrada em região tida como quilombola, similar a algumas peças constituintes da coleção africana do MPEG de Belém do Pará. A tomada de conhecimento desse objeto sobreveio ao momento em que concluíamos síntese de uma discussão sobre a procedência africana de contas de vidro encontradas em escavações arqueológicas em Santos, litoral de São Paulo, semelhantes a algumas existentes em coleções de diversas procedências cronológicas e culturais do acervo do MAE/ USP (Salum 2010).

\section{Desenhos e fotografias da África como fonte de pesquisa das artes ou de objetos artefatuais}

A análise das artes da África tem compreendido o estudo de fontes imagéticas envolvendo 
o desenho e a fotografia de diferentes cronologias. Dos registros dos viajantes e missionários a partir do século XV aos cartões postais da passagem do século XIX para o XX, temos uma farta documentação visual que ainda pode ser tomada como fonte e, portanto, instrumento metodológico, não fosse sua finalidade de então, que não nega sua natureza eurocêntrica. Diante disso, cabe analisar se é possivel considerar como evidência factual o que nos dizem as imagens missionárias e coloniais, bem como perguntar-se, nos dias atuais, qual o tipo de dado a ser obtido a partir de imagens dessa natureza.

Havemos de considerar que tratamos genericamente por "documentação" séries de registros que não são propriamente um repertório sistematizado e que apenas a partir dos anos 1990 começam a surgir disponíveis - caso dos arquivos sobre os bamum dos Camarões (Geary 1988), ainda que a preocupação com o assunto já viesse anteriormente mesmo que principiante (cf., por exemplo, Forlacroix, 1970, sobre a missão Binger-Monnier no final do século XIX).

Em um primeiro levantamento, Geary (1986) faz um apanhado geral sobre as pesquisas no assunto e observa que o tratamento do material histórico fotográfico feito na África vinha sendo usado em publicações onde as fotografias são em si mesmas o objeto investigado, e, no caso de publicações acadêmicas, servindo de fonte primária para outras análises históricas, além de servir como ilustrações desde textos eruditos a livros ilustrados de estórias populares. Raramente, esse tratamento consistia em pesquisa primária de acervos fotográficos específicos ou da obra de um único fotógrafo. Vê-se então, que, ainda nesta época, contava-se com muito pouco na matéria - pouco além, aliás, do que nucleou o trabalho que a autora vem realizando sobre os arquivos da expedição alemã aos Camarões entre 1884 e 1915 (Geary1988).

As imagens fotográficas fornecem, por vocação, tipos específicos de informação e, assim, elas couberam com grande propriedade ao desenvolvimento dos estudos de história da arte e de cultura material. De certo modo, serviram como resgate de toda produção sobre a história da arte africana que vinha sendo realizada desde os anos 1930 firmemente vinculada às disciplinas humanísticas, em particular à antropologia, desde a organização dos grandes museus europeus como o Musée Royal de l'Afrique centrale-MRAC, Tervuren.

Em parte é graças a essas imagens que se tem contextualizada a maioria das peças que foram levadas da África por pelo menos quatro séculos que precederam o fato colonial nesse continente, acumulando-se com a pilhagem realizada durante a primeira metade do século XX até pelo menos as independências dos países africanos - coletas que não foram, em seu tempo, devidamente sistematizadas. Em contrapartida, nesse tipo de imagem está imbuída a visão etnocêntrica do projeto e do uso a que foi destinada, entre eles a propaganda colonial (Fig. 1).

Os anos 1980 e 1990 foram prolíferos na difusão e crítica do conjunto dessa iconografia, passando a ser usado também como suporte do tratamento da arte africana. O Musée Dapper, Paris, reinicia, a partir de sua fundação em 1986, a publicação sobre arte africana que se via praticamente paralisada na Europa desde os anos 1970. Veio com o mote "um espaço para as artes e as culturas da África, Caribe e suas diásporas", quando as instituições europeias começavam a se preocupar com o peso do patrimônio material levado da África e repercussão que isso começava a tomar, sobretudo na produção do conhecimento. Em grande parte dos títulos que o Musée Dapper tem publicado transparece uma linha editorial que privilegia a pesquisa de fontes etnográficas, sobretudo das ilustrações de viajantes (cf., entre outros, Husson et al. 1989 e Cornet et al. 1997). No mesmo período, a revista African Arts, da UCLA, Los Angeles, lança números especiais, tais como um sobre fotografias históricas da África (Historical 1991), prenunciando o desenvolvimento da área de antropologia visual naquele momento e novas perspectivas nos estudos da arte africana também nesse caminho.

Mas a iconologia construída a partir da África passou a receber tratamento diferencial em torno dos anos 2010. Os cinquenta anos da independência do Congo parecem ter desencadeado a guinada que o MRAC, de Tervuren, 


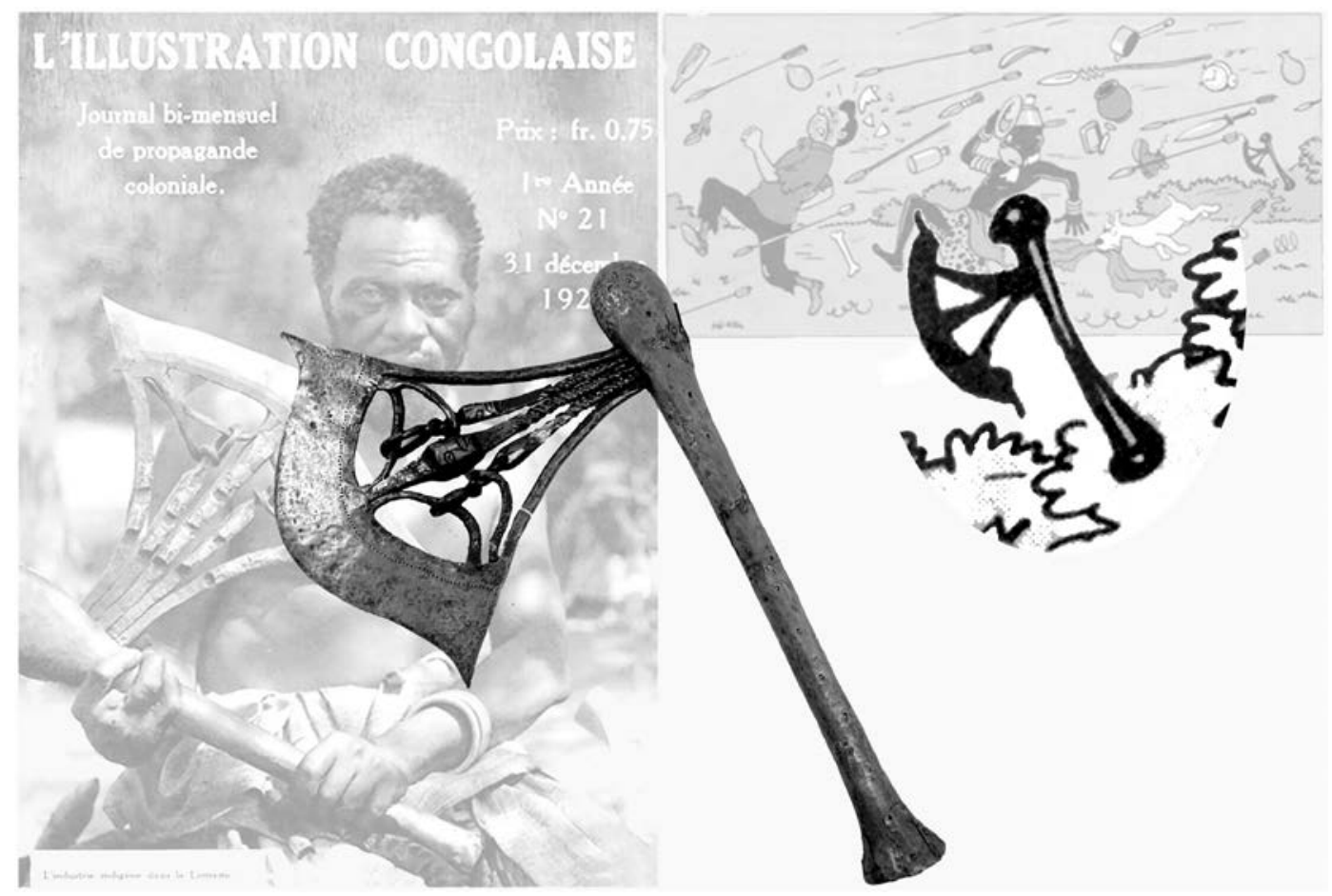

Fig. 1. Machado basonge (R.D.Congo), Acervo MPEG (fotografia da autora, 2009; direito de uso MPEG/MCTI), sobrecapa da revista de propaganda colonial belga L'Illustration Congolaise, I (21), 1924, também editada em cartão postal [s/fonte]. Esse tipo de machado, dito kilonda, é atribuído aos beneki - um dos subgrupos dos basonge, ou songye. Através dele e de outros objetos, a metalurgia e a imagem da África e dos africanos foi depreciada, como nos quadrinhos Tintin au Congo de Hergé. Com outra abordagem conceitual, esta figura inspira-se em montagem similar à publicada em Lefebvre e Danny (2011: vii), sendo esses machados cerimoniais tidos como itens de coleção desde longa data.

já vinha tentando dar através de sua produção editorial, como o primeiro catálogo sistemático de suas coleções do Congo, Trésors d'Afrique (Verswijver 1995), sendo também época em que surgem amostras de compilações fotográficas analisadas por especialistas em edições de catálogos de exposição (cf. Vellut 2005), também preocupadas com a herança filmica do cinema colonial (cf. Vanschuylenbergh e Aziza 2010).

Hoje, em vista dos impactos ainda atrelados à colonização e à escravidão africanas, os estudos de imagem na Europa sobre a África podem prestar-se às questões de memória, patrimônio e identidade, que são, aliás, tomados como objeto por todas as disciplinas das ciências humanas voltadas para a África, a fim de rever a história escrita da África que não pode mais ser vista sem sua "diáspora" pelo Atlântico. Além disso, se antes esses estudos estavam atrelados ao conhecimento do Outro, hoje eles não se sustentam se não diante do reconhecimento das atrocidades coloniais implicadas na coleta dos artefatos e registro dessas imagens - indeléveis e a serem reveladas em toda a sua essência; inócuas sem essa revelação. Note-se ainda que, levando-se o que precede em consideração, não se tem um corpus de referência que possibilite trabalhar com as imagens disponíveis, ainda mais sem se saber qual tipo de informação precisa pode ser obtida a partir das existentes. É também necessário pautar, em cada caso específico, se fotografias e desenhos publicados na literatura colonial ou missionária teriam verdadeira dimensão histórica enquanto testemunho, enquanto fonte de pesquisa. 
Como especialista na matéria, Christraud Geary exemplifica como a potencialidade de uma imagem enquanto fonte histórica pode ser obscurecida, mas também como ela pode revelar personagens e fatos para além do que interessava à fotografia colonial, documentando a própria história da colonização entre outros fatores. Trata da análise de originais (negativos) e cópias de uma mesma fotografia retratando um personagem ligado às artes, bem como ao reino de Kom dos Camarões e ao período da tomada do palácio pelos alemães em 1905. Suas legendas só levaram a identificações contraditórias, antes que outras análises de objeto e imagem, incluindo-se as relativas à tradição oral, resgatassem seu valor, para além do registro de um chefe-escultor dos Camarões - sendo só isso o que essas legendas, de início, indicavam como denominador comum (Geary 1986: 103-106).
Sem o recurso da documentação de que se nutre a autora, porém, temos um caso similar que se poderia aplicar em uma perspectiva museográfica sobre a imagem do célebre cartão de Edmond Fortier, em que a identidade dos fotografados é deformada: seriam curandeiros, sacerdotes ou chefes os homens que empunham cetros típicos do ex-Reino de Daomé no início do século XX (Fig. 2)?

Esses dignitários ali fotografados são provavelmente fon (povo situado na atual República do Benin) e nos permite aqui introduzir alguns aspectos mais propriamente concernentes à identidade e representação de culturas africanas no Brasil, como a da "nação mina" - expressão usual, mas polêmica na produção acadêmica, que, de acordo com João José Reis, se refere a um conjunto que encerra diversos grupos de africanos escravizados no Brasil trazidos do

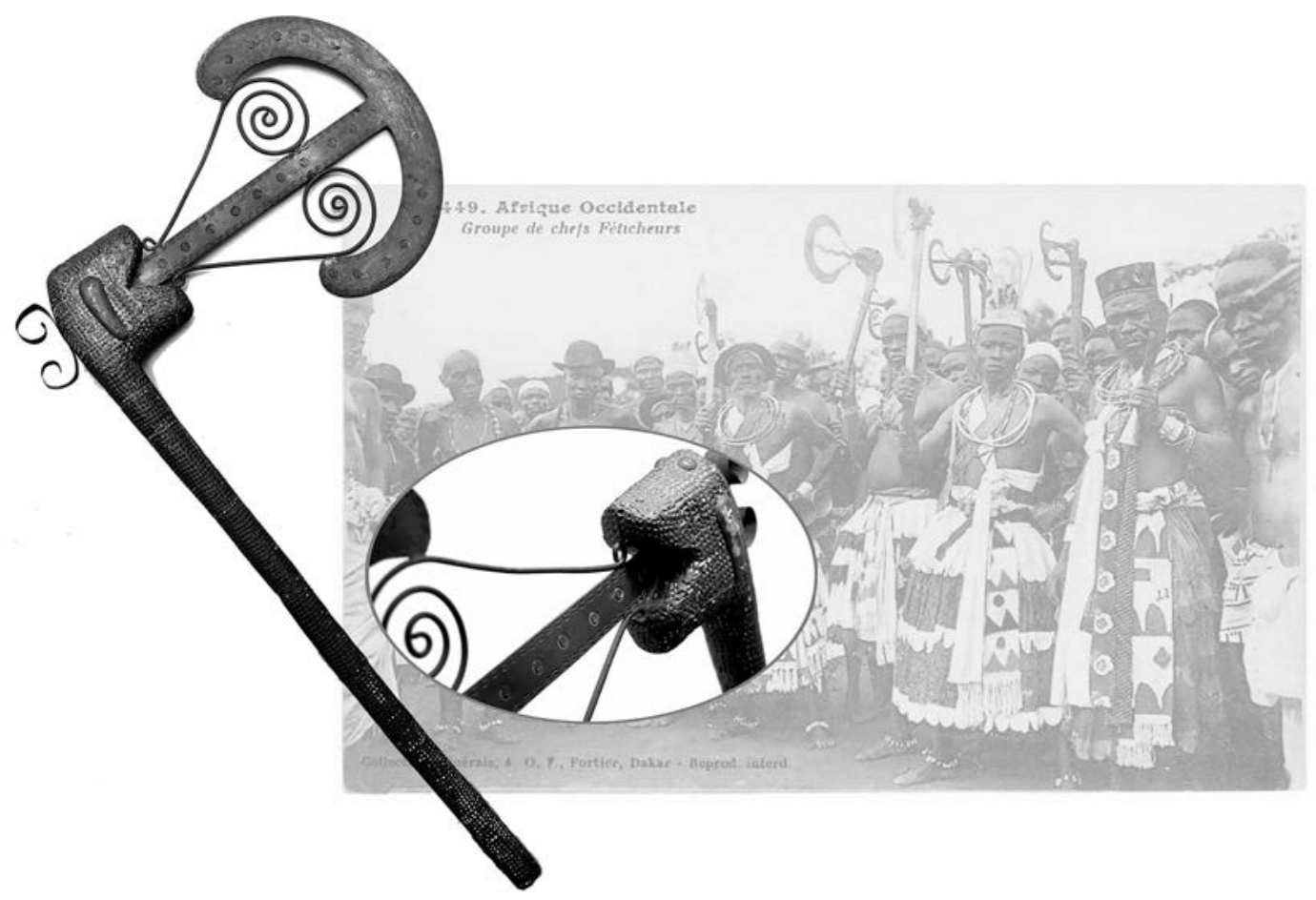

Fig. 2. Bastão ou bastonete fon, Rep. Benin, Acervo MAE/USP (fotos da autora, 2011 CMAE/USP), sobre cartão postal de Edmond Fortier, à venda pelo site da Internet (postcards > Africa > Benin / fortier - Delcampe.net, acesso 8/5/2009, também publicada como "Fête à Abomey (1908) - Groupe de chefs Feticheurs" na página da Internet do CENTRE EDMOND FORTIER/ Exposition Benin 1908 Repro-active jan.2004, http://home.planet.nl/ kreke003/ ben449.htm. Objeto tido como insígnia do ex-reino de Daomé, e conhecido como récade ("cetro", em francês). 
Golfo do Benin em períodos diferentes, não podendo se caracterizar como um agrupamento étnico no sentido estrito do termo (cf. Reis 2003). Ainda que o estudo desses aspectos e da história dos africanos no Brasil se expanda para uma problemática de outra natureza, ela não deixa de incluir temáticas relativas ao postal de Edmond Fortier, que dão sentido a objetos presentes nas coleções do MAE/USP, trazidos da África por Marianno Carneiro da Cunha, representando justamente essa região e esses grupos escravizados no Brasil (Fig. 3).

O recente artigo de Sandra Graham (2012), intitulado "Ser mina no Rio de Janeiro do século XIX", detém-se sobre a estória de um casal alforriado na metade do século XIX, ambos trazidos da Costa da Mina (Golfo do Benin) para Salvador-BA como da região iorubá, vendidos em seguida para senhores do Rio de Janeiro, onde se conheceram, cerca de 1840. Chamavam-se entre si de "mina", que poderia compreender também daomeanos de língua gbe (como, entre outros, os fon), e iorubas, como eles próprios eram - o que ficava nela visível pela exibição que fazia no uso de panos da costa importados do território iorubano para o Brasil, e nele, mais ainda marcadamente visível, pelas escarificações faciais típicas. Observações muito próximas dessas características de africanas e africanos escravizados no Brasil, tidas como marcas identitárias, são bem conhecidas e encontram-se também no pequeno texto "olhar

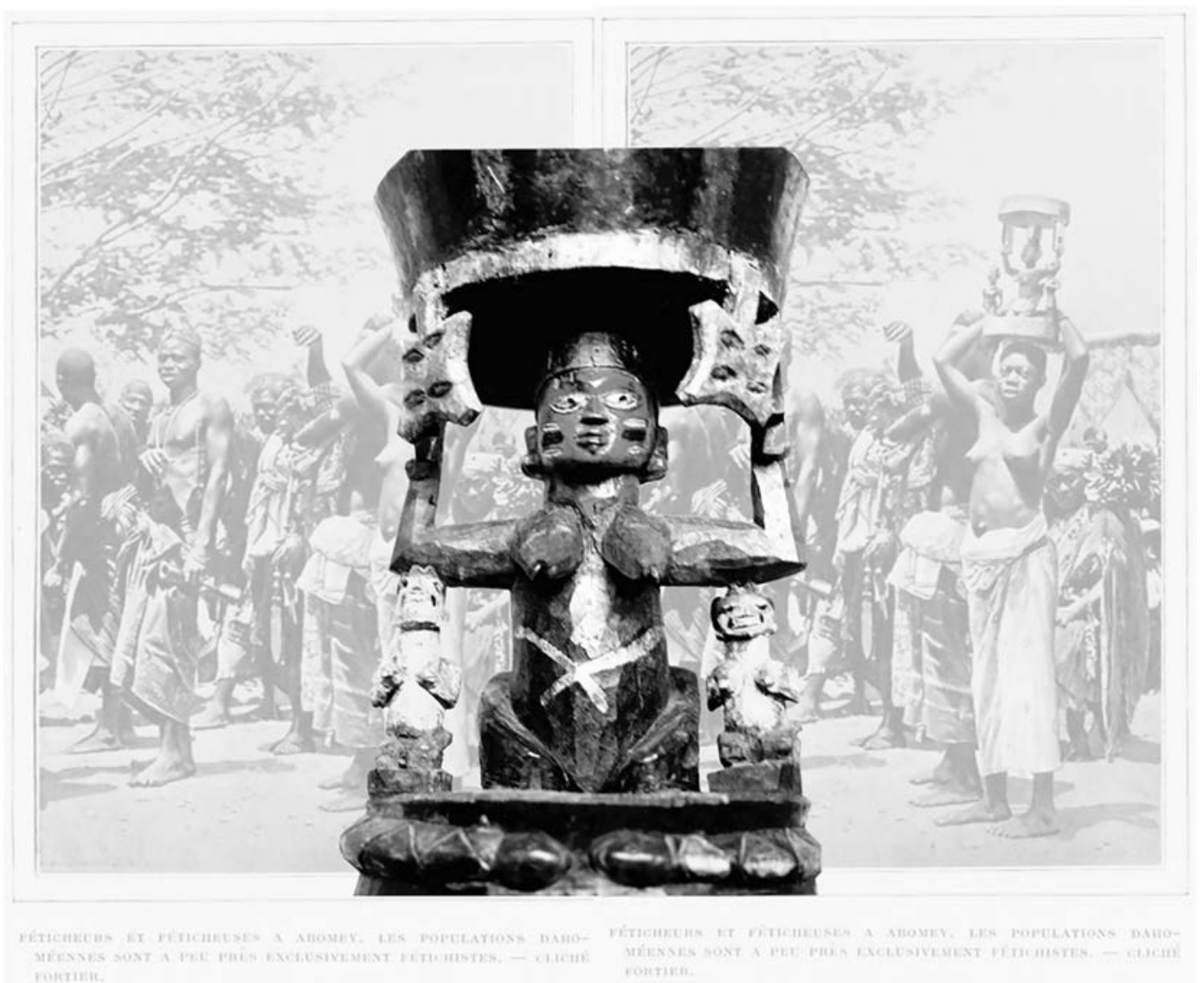

Fig. 3. Pilão de xangô, iorubá/nagô, Nigéria/Rep. Benin, Acervo MAE/USP (foto da autora, 1999), sobre foto de Edmond Fortier. Image ID: 1267597 - Féticheurs et féticheuses a Abomey. Les populations Dahoméennes sont à peu près exclusivement fètichistes (1912), publicada em New York Public Library Digital Collections Website Image Digital ID: 1267597, Record ID: 666042, Digital Item Published: 9-9-2005; updated 3-25-2011. 
escravo, ser olhado" de Manuela Carneiro da Cunha sobre a fotografia de Christiano Jr. (in Azevedo e Lissovsky 1988: 23-30). Mas raro é ter-se como referência dessas marcas identitárias, como se tem em Graham (2012: 47-51), indicações bibliográficas como de Henry John Drewal, historiador da arte e especialista dos iorubas na África e nas diásporas (cf., entre outros, Drewal in Abiodun et al 1993), e de Eugenia W. Herbert, historiadora da África e autora de um trabalho clássico sobre a metalurgia e rituais de transformação nas sociedades africanas (Herbert 1993).

Isso revela a importância dos estudos de arte africana, que, em particular desde os anos 1980, têm sido tomados na abordagem de aspectos africanos de outras disciplinas, seja da cultura material quanto de formas imateriais da cultura, e seja da África quanto de contextos negro-africanos no Brasil - neste caso para além do que se refere aos candomblés ou religiosidade.

Sabe-se que as escarificações no rosto de africanos escravizados nas Américas poderiam, por serem parte de sistemas gráficos próprios de culturas africanas específicas, permitir identificar as localidades de origem e a denominação familiar de muitos deles. Mas a eles foram também associados estereótipos de conduta e pertencimento na sociedade escravagista o que poderia ter sido incorporado como sinal distintivo de identidade sociocultural em indivíduos e grupos determinados no novo contexto para o qual foram trazidos, ou no qual foram inseridos, não nos cabendo, entretanto, tratar dos fenômenos pelos quais se deram novas formações de identidades étnicas no Brasil entre os africanos trazidos para cá como escravos.

O que podemos dizer em relação a isso é que os sinais gráficos dos cabinda, angola ou congo do Brasil podem ter sido recriados em outros suportes junto dos nagôs, iorubás ou minas no país, o que consideramos poder corresponder com o que Kabengele Munanga nos diz sobre a construção das identidades socioculturais:

"É verdade que num país como o Brasil, as cercas do diálogo entre culturas e identidades vacilam, os sangues se misturam e os deuses se tocam. Nem por isso, as identidades, enquanto processos, se interrompem ou se confundem, pois em todas as filosofias os termos 'ser' e 'existir' partem do princípio ontológico da diferença" (Munanga 2004).

Tomando essa inspirada citação de Kabengele Munanga como se fosse nossa, caberia pensar-se na linguagem gráfica artefatual, arquitetural ou impressa no próprio corpo à vista da multiplicidade diversa de símbolos africanos que convivem, independentemente de sua procedência cultural ou histórica, nas expressões do que é ser negro no Brasil, remetendo-nos para outro texto de Munanga (2000) em que ele elenca características de identidade nas artes plásticas afro-brasileiras, como para o de Marianno Carneiro da Cunha (1983) que trata disso também.

É ainda necessário que saibamos diferenciar a África do Brasil e declinar das alusões fictícias sobre o continente africano que a iconologia colonialista cristalizou.

\section{Alteridades entre arte e cultura material, e o surgimento de um gládio de conformação "bantu" em área de quilombo}

Desde os primeiros estudos sobre o negro no Brasil vê-se a importância dada à cultura material tanto da África quanto dos africanos e seus descendentes no Brasil. O olhar para essa cultura material, entretanto, pesou para seu lado estético e sempre esteve voltado justamente à área geográfica da África mais aludida nesses primeiros estudos, atinentes aos candomblés da Bahia, cuja origem jêje-nagô foi mais imponente e visível até os anos 1970. Pouco se considerou sobre a tecnologia e os materiais e foi pelos materiais que fomos levados a abordar o conjunto de conhecimento relativo à arte africana da África central.

Primeiramente ativemo-nos a uma estatuária em madeira da República Democrática do Congo de grande importância e extensão, e de então pouco conhecida, a dos basonge, ou songye (Salum 1990) e, depois, a que se estende dos baluba aos bakongo (Salum 1996), estando aí implicada a consideração da existência das múltiplas ramificações étnicas que se formaram e se diluíram no tempo entre esses povos, sobretudo em razão da penetração europeia no interior da 
África central a partir da segunda metade do século XIX e da situação colonial implantada poucas décadas depois. Corresponde a esse período o reconhecimento dessa estatuária dita "tradicional", que durou até as vésperas da descolonização antes que ela viesse a ser retomada paulatinamente a partir da década de 1970. Mas a produção de objetos significativos ou simbólicos para o comércio nasceu bem antes desse momento de ruptura. Confira Steiner (1994), que, embora trate do tema analisando os mercados de arte de Abidjan na Costa do Marfim na década de 1980, aborda a dimensão comum do problema em todo o continente africano.

Naqueles anos de 1980, estudar o tema no Brasil inseria-se na preocupação com o incremento dos estudos africanistas, ainda raros entre nós. Deve-se lembrar que foi nessa época que ressurgiu uma nova fase da produção acadêmica associada a esse campo de estudos no país, que são os estudos voltados para o universo afro-brasileiro, sobretudo para os candomblés. Apesar de tudo, pouco de novo, para além das análises estéticas, foi produzido sobre a cultura material relacionada aos cultos e aos terreiros propriamente (cf. uma síntese sobre a produção anterior em Salum 2004), sendo que, entre os trabalhos mais recentes, poderíamos destacar poucos na área, como o artigo de Rita Amaral (2000) e a dissertação de Ademir Ribeiro Jr. (2008).

Voltar-se para os estudos da estatuária da África central, e do Congo em particular, sem pesquisa no campo sociocultural e de uma época passada - foi o que se deu conosco - é voltar-se também para aspectos da administração colonial e para as instituições belgas, pois vem daí o próprio objeto de estudo como também a documentação escrita existente relacionada.

Enquanto que fora do Brasil ainda tínhamos presente na Europa a importância de estudos estilísticos sobre as artes do Congo em uma tradição que vinha de Frans Olbrechts - somente em 1982, Joseph Cornet veio a publicar Art royal kuba, uma das últimas obras dos grandes especialistas europeus nessa linha -, no Brasil a efervescência da produção acadêmica sobre os candomblés estimulava a revisão das coleções africanas em museus que são em grande parte formadas por peças procedentes da África ocidental, particu- larmente de povos do Golfo do Benin, como os iorubás, em correspondência com a pesquisa desenvolvida de então entre nós, como já foi dito.

O que podemos observar disso é que a procedência dessas coleções em museus do Brasil e a tônica do percurso dos estudos africanistas no Brasil sempre se endereçaram mais para os problemas da escravidão do que para os problemas africanos propriamente ditos, ainda que se trate, em ambos os casos, de fenômenos e circunstâncias históricas dialéticas, mais do que indissociáveis.

Com a perspectiva de ampliação dos estudos das relações atlânticas na década de 1980, marcada especialmente pelo Congresso Internacional Escravidão da Abolição de 1988 organizado pela Faculdade de Filosofia, Letras e Ciências Humanas da USP, configuraram-se novos caminhos que hoje ganham luz face a essas coleções, ou face ao que essas coleções se referem, na investigação de contextos negro-africanos no Brasil. Há nelas, como no caso das coleções do MAE/USP, importantes testemunhos materiais dos iorubás e dos fon. São testemunhos também do tempo em que se deu o tráfico, pelo menos do período correspondente às últimas levas de africanos trazidos como escravos pra as Américas, às revoltas escravas do início do século XIX, ao retorno de africanos para a África. Que seja lembrado, trata-se de artefatos produzidos no início da década de 1970, encomendados por Marianno Carneiro da Cunha a artesãos locais, de modo que se associam a realidades históricas africanas do passado e do presente. Do ponto de vista formal e material, extrapolam o uso da madeira e o fato de se constituírem ou não estatuetas: valem-se também do metal e de outros materiais heteróclitos. Muitos desses testemunhos, com elementos e formas simbólicas, são constituídos pela própria matéria bruta - um fator cuja compreensão não prescinde da remissão a formas de pensamento e de cultura material que já nos vinha de outras áreas da África através da noção de nkisi (cf. Salum 1988, 1990 e 1996).

A noção de nkisi (pl. minkisi) povoa as ideias sobre os povos de línguas bantu desde as primeiras referências aos bakongo, com que os viajantes europeus da era dos descobrimentos toma- 


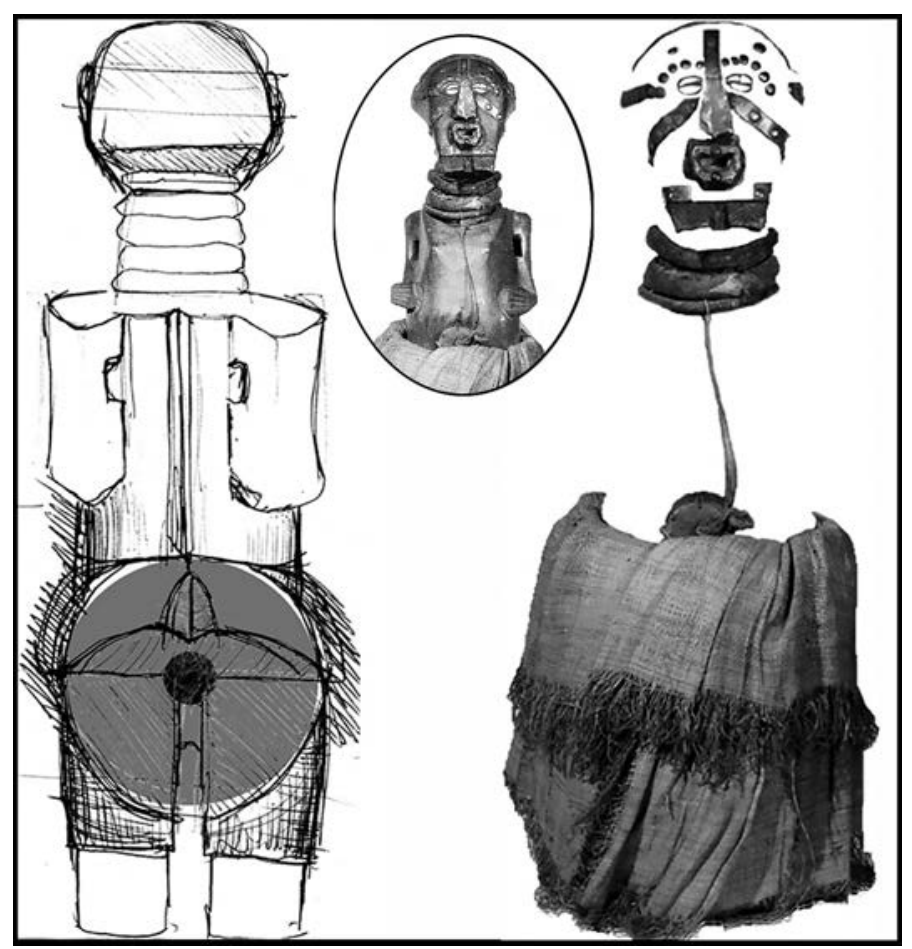

Fig. 4. Estátua songye ou do basonge, R.D.Congo, MRAC, Tervuren (foto e desenho da autora, 1984). Minkisi (sing. nkisi) é nome genérico em kisonge (ou kisongye) de esculturas antropomórficas consideradas "objeto de força", como designa o termo em outras línguas bantu da África Central, ainda que entre os bakongo e outros, o uso de minkisi não se restrinja a estátuas e estatuetas. Diz respeito ao potencial do universo das coisas materiais que, nas estátuas songye está nas substâncias e elementos nelas introduzidos e superpostos, e na própria matéria de que são feitas.

ram contato precoce, o que já é documentado, já no século XVII, por Olfert Dapper (1989: 335): "Esses etíopes chamam Moquisie ou Mokisses tudo aquilo em que reside, na sua opinião, uma virtude sagrada e incompreensível que lhes faz bem ou mal, e [usam isso] para descobrir as coisas do passado e do futuro." (Fig. 4).

Mas seria possível estabelecer uma aproximação conceitual dos minkisi com os bochio, botchio ou "botiô" dos povos do Golfo do Benin, no que diz respeito ao seu aspecto material e alquímico - noções depreendidas de Susan Blier (1995) e Marc Augé (1988). Que seja enfatizado o fato de que os minkisi e os botiô são, em sua origem africana, fundamentados em complexos culturais distantes na África ainda que passíveis de serem aproximados no encontro de suas tradições nos candomblés (Salum 2008), onde temos também a presença de uma linguagem gráfica simbólica cuja presença se assinala em vários outros contextos das Américas através dos "pontos riscados", tidos como dos bakongo (cf. Thompson 2011: 107-119).

Trataremos adiante de estudos sistemáticos sobre grafismos de culturas África central, mas já começamos por aqui tocar, apenas, no que foi encontrado na decoração da lâmina da "lança quilombola" tomada como fio condutor deste artigo, grafismo este que se tem como um dos índices de sua proveniência geográfica-cultural, cabendo discutir-se a quais dimensões contextuais desse objeto ela nos levaria. Veremos.

Childs e Killing (1993) fazem um apanhado sobre a metalurgia na África pré-colonial, quando de sua retomada por arqueólogos em meados do século XX, reportando-se à importância dos estu- 
dos de arte africana, lembrando que foi apenas através do saque da Expedição Britânica de 1897, por que foi revelada ao mundo a arte escultórica do Reino de Benin, que as ciências do mundo ocidental começaram a perceber a dimensão cultural da metalurgia da África. Compreendendo a tecnologia enquanto processo dinâmico e ideológico, os autores apontam perspectivas de pesquisa concernentes à transmissão da experiência africana com os metais para as Américas.

Muitas das formas simbólicas compreendidas através dessa dimensão social e cultural da metalurgia revestem-se de um segredo a ser desvendado, e assim vimos ressurgir, como dos filmes remasterizados do período colonial (Van Schuylenbergh e Aziza 2010), um apelo para examinar a dita "lança quilombola" conservada no Museu Sociorreligioso Dom Clemente José Carlos Isnard, de Macabu, vizinha de Campos de Goytacazes onde ela foi encontrada por mateiros em área que, conta a tradição, existiu um quilombo, cuja liderança seria Carucango, moçambicano, conforme registro em cartório local. Duas peças do MPEG, em Belém, são de feitura e aparência muito próximas a esta do Museu de Macabu - motivo pelo qual aceitamos colaborar com uma das séries brasileiras do programa "Detetives da História" centralizada nesse objeto, produzida pela Giros em 2009-2010 para o Discovery Channel do Brasil (Fig. 5).

Naquele momento, tínhamos acabado de realizar o primeiro levantamento das armas da coleção africana do Museu Goeldi, e, no mesmo período, apresentado uma síntese bibliográfica sobre um tipo de contas de vidro atribuídas à África chamadas de chevron, star beads, perla rosetta no Congresso da SAB em Belém (cf. Salum 2010). Seria mais um objeto associado aos africanos, além dos de cultos afro-brasileiros, que entraria no rol das nossas preocupações com os estudos de coleção de etnologia africana, do tipo já reconhecido pela etnografia, bem como pelo imaginário fomentado por ela.

A diferença é que essa arma nos remetia aos estudos que desenvolvêramos antes sobre os songye e outros povos do sudeste e sudoeste do

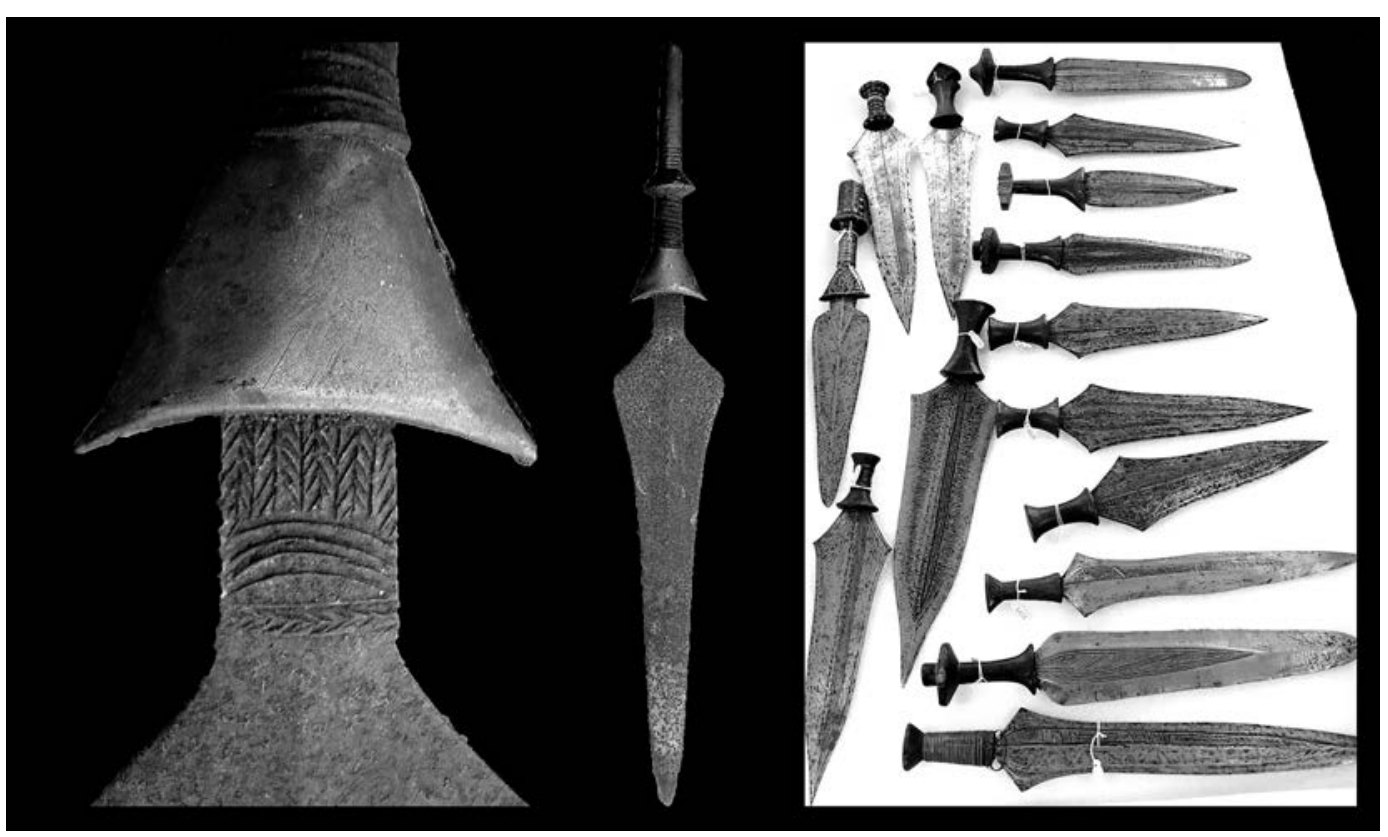

Fig. 5. À esquerda, espada curta, gládio, punhal, faca ou "lança quilombola", Acervo Museu Sociorreligioso Dom Clemente José Carlos Isnard (fotografia de divulgação concedida pela Produtora Giros, 2009), que pode ser relacionada (pela forma) com algumas das armas de lâminas retas e simétricas do acervo MPEG, à direita (fotografia da autora, 2009; direito de uso MPEG/MCTI). 
ex-Zaire e que temos retomado junto ao Museu Goeldi. No preparo para a entrevista, encontrei apenas romances e escritos de memorialistas locais, como os de Marcelo Abreu e Hélvio Gomes Cordeiro, com quem mantive contato por email. Essa bibliografia, no entanto, pouco acrescentou à análise do objeto que tinha diante de mim.

O levantamento de referências sobre a peça foi igualmente difícil. A classificação da coleção do MPEG foi feita por Peter Paul Hilbert (1914-1989). Pesquisador alemão, escritor e arqueólogo, ele havia vivido na África, Namíbia, e, ao chegar em Belém, em 1948, trabalhou com a coleção etnográfica africana, baseado, conforme dizem Figueiredo e Rodrigues (1989: 180), em sua experiência no estudo da cultura material africana e em fontes publicadas. Mas Hilbert não deu continuidade a esse trabalho, enveredando-se para a pesquisa amazônica. É uma classificação antiga, que pode ser revista. Mas por que meio? É preciso fazer a normatização da nomenclatura e dos agrupamentos sem que não tenhamos uma base sistematizada que congregue todos os termos encontrados.

Alguns gládios e punhais que Hilbert determinou como basonge (songye), Westerdijk (1975) e Elsen (2003) apontam como mongo, considerando-se o formato da lâmina e a empunhadura, ou o formato e decoração da lâmina. $\mathrm{O}$ grande território mongo estende-se ao noroeste do atual Congo, e é fronteiriço ao dos basonge, no sudeste do país, compreendendo os lokele, saka, kutu, tshoko, nktshu, entre outros povos relacionados. Westerdijk (1975) refere-se a tipos de armas mongo do Museu de Rotterdam que nos parecem corresponder ao do gládio encontrado em Goytacazes. Já, Elsen (2003: 202), em catálogo do Musée Barbier-Mueller, publica fotografia de "dois saka", da chefia Nkole, território Bokungu (c.1920) com arma composta de outro tipo de lâmina, cujo formato se vê em gládios atribuídos aos basonge no Museu Goeldi. No catálogo Beauté Fatale (Crédit Communal 1992) não parece haver grandes divergências desses dados, nem no de Lefebvre (2009). A descrição dos grafismos dessas peças tidas como songye no MPEG corresponde a alguns dos grafismos típicos que assinalamos na análise de detalhes decorativos de penteados da estatuaria
(Salum,1990), mas não temos conhecimento de um repertório específico que permita atestar aí um dado de procedência sociocultural (Fig. 6).

Resta de tudo isso apenas a expectativa de um cruzamento de informações que aqui apenas se esboça, sem que tenhamos fontes seguras, ou, pelo menos, normatizadas. Afinal, armas como essas já eram difundidas pelo comercio local provavelmente muito anos antes de, já no final do século XIX, estarem constituídas como coleção às vésperas de vir para o Brasil - os breves dados publicados de que se dispõe sobre o histórico da coleção africana do MPEG até o momento encontram-se em Hilbert (1961) e Figueiredo e Rodrigues (1988 e 1989).

Possivelmente houvesse respostas tecnológicas nesta direção das quais não temos conhecimento, mas algumas explicações etnológicas permanecem essenciais para a compreensão de algumas formas plásticas, como os grafismos, mesmo que a identificação de procedência de peças e grafismos típicos seja vulnerável diante das diferenças entre as mudanças sociais por que passaram as culturas africanas dentro e fora do continente, que o tempo cronológico não tem como equalizar.

Esperam-se ainda dados mais consistentes sobre a extensão da produção e uso de metais nas Américas como esperavam Childs e Killing (1993) vinte anos antes, assim como outras respostas específicas sobre o papel que os artesãos africanos trazidos como escravos pelo tráfico tinham na produção de metal nessas regiões. A pergunta com que esses autores terminam seu artigo é se funções sociais e simbólicas africanas do metal foram mesmo transferidas para o lado de cá do Atlântico, e, se, nesse caso, como teriam sido modificadas em suas novas configurações sociais. No universo das formas e dos ritos as imagens se complementam e se fundem (Fig. 7).

Embora tenhamos uma literatura importante sobre a religiosidade afro-brasileira da qual podemos depreender aspectos da metalurgia da região do Golfo do Benin presentes nos candomblés (Salum e Souza e Silva 2005-2006), há uma omissão de registros na metalurgia claramente discerníveis de origem bantu no Brasil talvez pelas modificações acima referidas.

Eugenia Herbert (1994: 90) refere-se a Pride of Men de Colleen Kriger, dissertação de 1993 a 


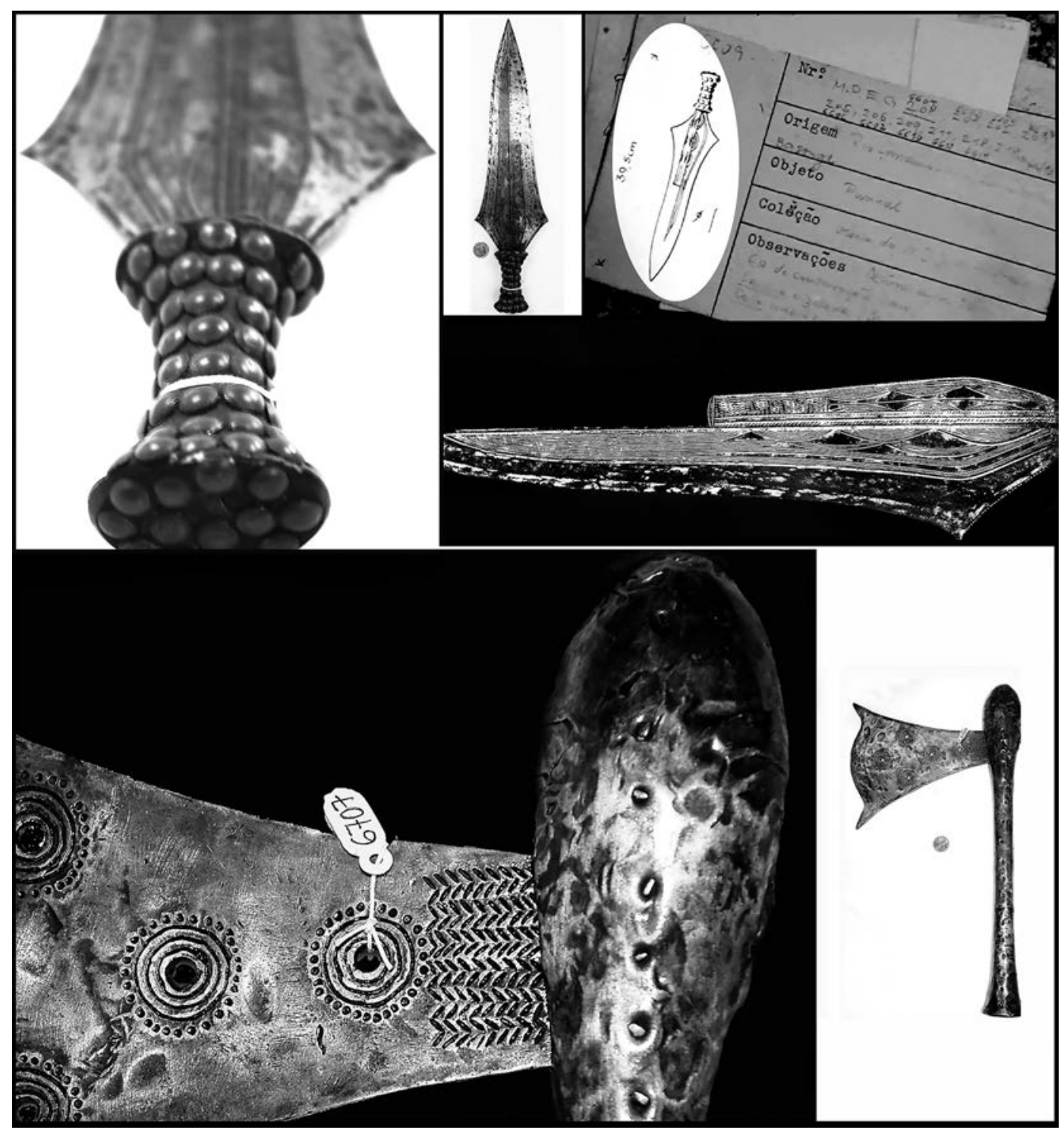

Fig. 6. Acima, "punhal feito de ferro" basonge (R.P.Congo), Acervo MPEG - visto também no desenho de Peter Paul Hilbert da ficha correspondente -, com empunhadura e lâmina de forma e grafismos lineares paralelos retos e em semicírculos, que, tal como em forma de losangos, semicírculos e zigue-zagues podem caracterizar a produção songye. Nos catálogos atuais, peças similares constam como lokele e topoke, do complexo mongo. Abaixo, vê-se um machado de cobre basonge, também do Acervo MPEG, com incisões geométricas igualmente típicas dos basonge, tido hoje como dos nsapo e outros grupos songye do leste, bem como dos batetela, idem do complexo mongo. Fotografias da autora, 2009 e 2012; direito de uso MPEG/MCTI). 


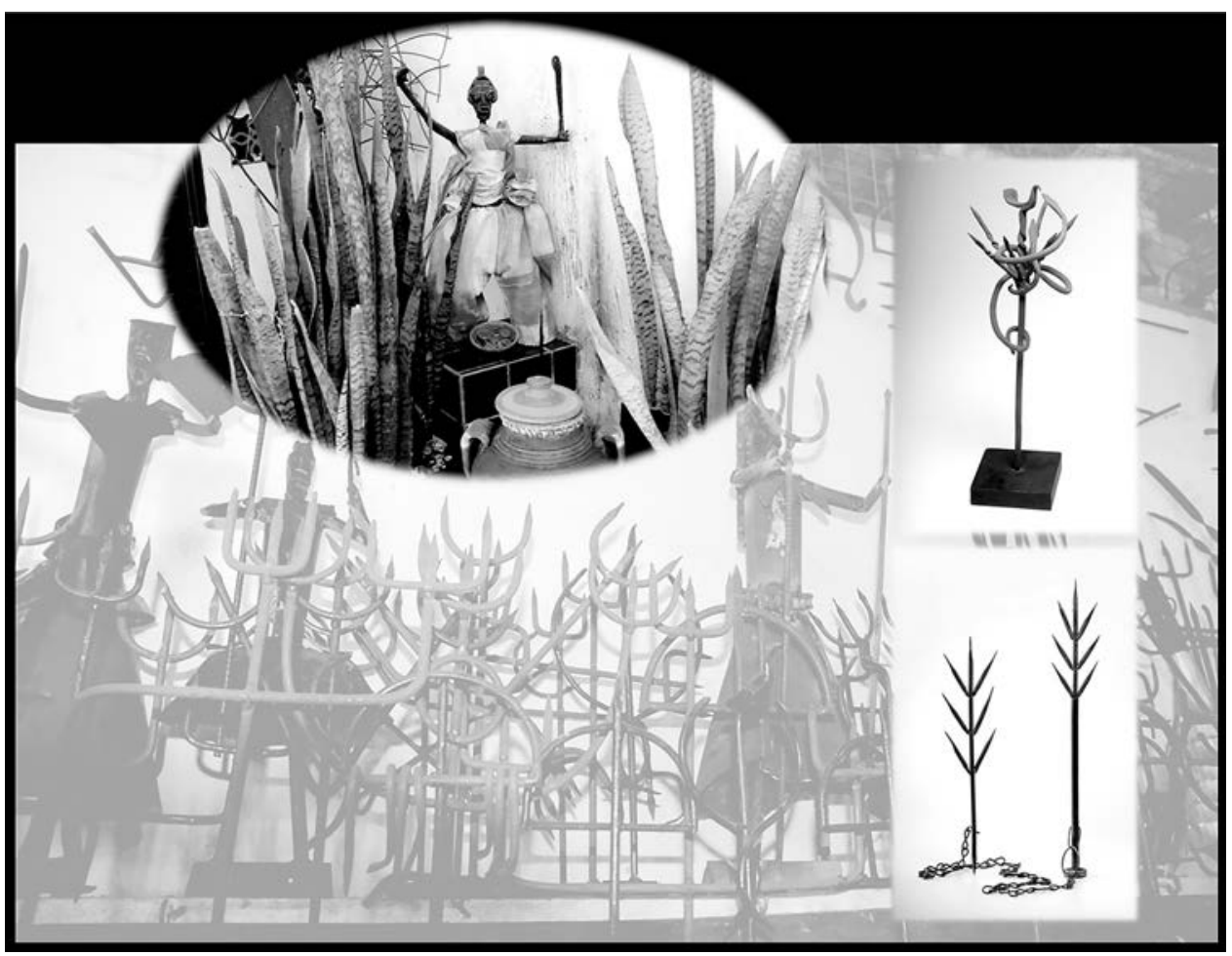

Fig. 7. Ferros de ossaim e de exu, Acervo MAE/USP (fotografia de Wagner Souza e Silva, 2003 CMAE/ USP) emoldurados por tomadas da Feira de São Joaquim, Salvador, e do Ilê Axé Opô Oyá Igbale, Lauro de Freitas (fotografias da autora, 2012), expressando o conjunto de abordagens contextuais que compreende várias modulações dos significados e funções desse tipo de produção africana no Brasil.

que ainda não tivemos acesso, como uma obra que não só critica tipologias anteriores, mas mostra como as armas funcionavam em um contexto histórico e sociopolítico. Já Juliana Ribeiro da Silva (2011: 19-21), na apresentação que faz dessa obra, destaca a importância do método words and things usado por Krieger, aplicado a um corpus documental diversificado em que se incluem elementos das línguas bantu e a cultura material. Não se sabe, porém, se dada a amplitude cultural dessa enorme área geográfica em que essas armas circularam - mesmo sem considerar com qual delimitação cronológica se trabalha, desde que antes do fato colonial - seria possivel estabelecer modalidades específicas do funcionamento contextual das armas que hoje se veem em coleção, sem recair na generalidade de seu emprego como insígnias chefais e bens de prestígio, havendo um raro catálogo sistemático sobre o assunto, ainda que restrito às coleções de Angola do Museu de Neuchâtel (Rodrigues de Areia e Kaehr, 1992). O acervo sobre o qual se reporta apresenta dificuldades documentais, mesmo assim preenchidas posteriormente, vendo-se as obras apresentadas no catálogo colocadas no que foi possível em seu contexto de uso, sendo elas em maioria reunidas pela missão científica suíça dos anos 1930.

Outras publicações sobre arte africana conservam o mérito de tratamento, mesmo que conforme o pensamento de uma época, do passado ou do presente, de uma matéria que não se sabe até quando seria alcançada pela memória dadas as transformações sociais transcorridas na África no século passado.

Inevitável voltar à resenha de Eugenia Herbert (1994) de Beauté Fatale: armes de l'Afrique centrale, destacando o que diz desde o início: 
houve tempo em que era preciso procurar armas africanas escondidas nos cantos de lojas de curiosidades "quando ainda eram classificados como artefatos, cultura material”. "Não mais", diz ela, observando que nos últimos 10-15 anos, elas foram redefinidas como arte. E o interesse sobre elas aumenta, o que se reflete, a nosso ver, no surgimento de La forma perfetta: sulle tracce della moneta africana (Ballarini 2009) quase vinte anos depois de Beauté Fatale, e nos preços que essas armas, e moedas, e todos os tipos de objetos das "négreries", como se dizia na Europa do início do século XX, que sobem na mesma proporção. Catálogos comerciais de época serviriam ainda hoje à consulta sobre procedência atribuída às peças integrantes desse mercado não fosse a produção editorial recente - ver de Crédit Communal (1992) a de colecionadores como Luc Lefebvre (2009) e Lefebvre e De Waele (2011) -, mas não deixam de nos informar sobre os tipos requeridos, ao gosto europeu da época (cf. Webster 1896 e Oldman 1903-1907).

Resta questionarmos sobre qual é a validade do estudo desse tipo de peça em coleção, resposta que apenas se esboça em vários vieses e nos vários textos de autores reunidos em Gonseth et al. (2002). Não parece mais possível diluir as barreiras das classificações étnicas, nacionais e globais, ou das artes tradicionais e universais, mesmo porque não se pode esperar que fosse possivel juntar peças de todas as culturas e de todos os tempos num único acervo, ou exposição. E se ainda isso fosse possível, não haveria parâmetros comuns na sua abordagem.

De tudo isso, resulta que se vê, em matéria veiculada pela Internet sobre o Museu Sociorreligioso de Macabu, a espada de feição africana que nos foi apresentada como "lança quilombola", dentro de uma vitrine circundada por instalações destinadas em sua maioria à imaginária católica - presença tão difícil de explicar quanto sua localização onde se estima ter existido o quilombo a que foi associada (cf. Olhar sobre Macabu, 2012). Vai do mesmo a identificação apressada com que foi etiquetada: em casos particulares, e por certos detalhes, se viu como songye; mas ela não pode ser identificada como songye - o que alerta para a necessidade de mais atenção no direcionamento da difusão e ensino sobre África no Brasil.

\section{Desenhos, grafismos e linguagem gráfica como fonte de pesquisa das artes ou de objetos artefatuais - um apanhado da expressão gráfica bantu a partir de dois}

A decoração de objetos não é aptidão exclusiva dos africanos, que também não detêm o uso do corpo como suporte de grafismos. Mas a partir do artigo de Gérard Kubik (1986) temos que o sistema decorativo em sociedades de línguas bantu constitui-se como uma linguagem simbólica de grande extensão, havendo poucos estudos sistemáticos sobre o assunto. Uma das referências mais importantes no estudo no problema é a pesquisa de Marie-Louise Bastin sobre a "arte decorativa” tshokwe (Bastin, 1961) havendo outra, de publicação posterior, de Joseph Cornet sobre a "arte real" kuba (Cornet 1982).

O ponto central existente no padrão de entrelaçado renomado entre os batshokwe, de nome sona, pode ser também analisado como derivação da técnica construtiva: os pontos marcados a dedo em torno dos quais a linha contínua serpenteia podem ser sinal deixado pelos desenhistas tshokwe e dos povos avizinhados como sua marca. Os sona são desenhos no solo, na areia, e que frequentemente são caracterizados pelo seu teor matemático. O plural de sona é tusona, mas, segundo Kubik (1986: 100), tusona é também o nome dessa tradição de ideogramas dito em língua lucazi dos ngangela, de que faz parte o sona tshokwe. Conforme assinala o autor, essa tradição ocorre em uma área de grafismos muito extensa, de vários tipos e suportes, que compreende Angola, Zâmbia e Congo, ex-Zaire (Kubik, 1986: 101). O sona tshokwe, porém, não tem correspondência nos quarenta e cinco motivos decorativos encontrados por Marie-Louise Bastin com suas numerosas variantes em cada caso, que, em poucas palavras, constituem desenhos das incisões nos objetos, tatuagens e escarificações, como também dos próprios trançados da cestaria e tecelagem (Fig. 8).

O corpus documental de Bastin constituiu-se de quatrocentas peças levadas ao Museu do Dundo a partir do final do século XIX e duzentas fotos correspondentes da arte tshokwe, lwena, lunda, minungu, sinji e mbangala. $\mathrm{O}$ 


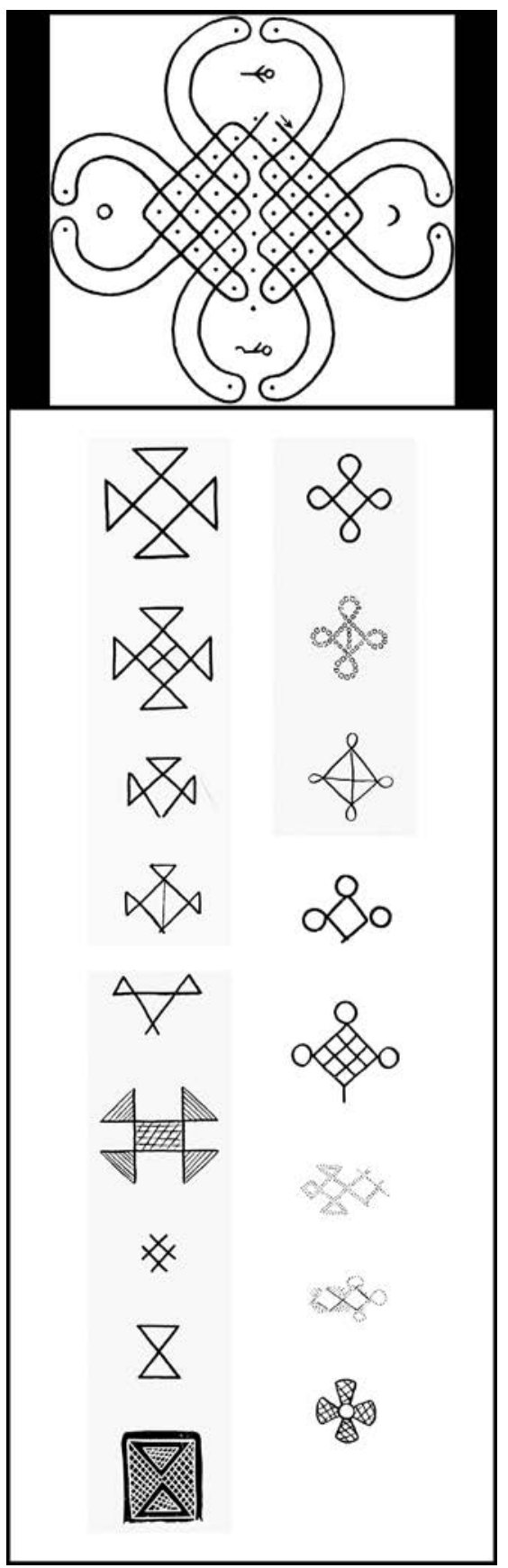

Fig. 8. Kalunga, "Deus", figura desenhada na areia - um desenho sona tshokwe publicado em Bastin (1961: 39). Seguem-se as variantes de um dos tipos de motivos decorativos da Lunda encontrados na análise da arte tshokwe pela autora, chamado cingelyengelve, que é aplicado em escarificações e adornos corporais de metal (Bastin, 1961: 147-151). estudo desse material foi associado a trabalho de campo por cinco meses entre especialistas do nordeste de Angola de 1956 - da fundição, da cestaria, e de fabricantes de bainhas, invólucros, estojos, assim como de tocadores de instrumentos musicais e escultores (Bastin, 1961: 19-20 e 221-223). Verificou que os nomes de muitos motivos decorativos nos objetos correspondem ao nome de objetos do cesto de adivinhação tshokwe ngombo, de modo que cada motivo de decoração, mesmo que em suportes e procedimentos técnicos diferentes, figura como que evocando simbolicamente parte deste que é considerado um microcosmo da vida desse povo - cf. Rodrigues de Areia (1985) a quem se deve o trabalho mais consagrado sobre o assunto.

Marie-Louise Bastin também sustenta que grande parte dos motivos decorativos que levantou foram gerados a partir da cestaria. Os tipos morfológicos desses motivos decorativos podem ser considerados ideogramas sugerindo uma significação simbólica que "têm ainda ou tiveram" na decoração de objetos de técnicas diferentes, como escreveu Bastin (1961: 222; cf. tb. p. 62).

Há que se observar aqui que os processos produtivos da cultura material como construção social também foram evidenciados pelos estudos de grupos indígenas brasileiros há várias gerações de pesquisadores. Neles se observa a relação entre aspectos coletivos e individuais de expressão de concepção de mundo através das artes gráficas na cestaria, na cerâmica e no corpo humano (cf. uma síntese em Vidal 2001).

O corpo como suporte de inscrições gráficas, e sua vocação como manifestação de identidade sociocultural é tratado em um artigo clássico de Terence Turner (1980) e referência nos estudos de etno-estética. Tratando dos índios kayapó, o autor mostra níveis de diferenciação biológica e psicológica do indivíduo a partir da constatação da superfície do corpo como limite, mas também como fronteira do "eu" social. Sobre esta, para além da diferença entre os individuos entre si, há um nível mais profundo a ser considerado que são as modificações na pele associadas a classes sociais. Daí 
o autor concluir perguntando-se, ou perguntando-nos, se estamos nos reportando a uma expressão distante do nosso próprio código de vestuário e aparência ou se ele seria um dispositivo cultural do mesmo tipo. Projetando isso em sociedades em situação colonial e em pleno contato com os europeus, como os batshokwe e bakuba, quando os estudos sobre seus grafismos se deram, é de se pensar se faria sentido tratar essa "pele social" como étnica-cultural, a partir de quando e até quando.
Passaremos agora ao sistema decorativo dos bushoong, generalizado como kuba, de grande sofisticação e beleza. Lembramos antes que os bakuba tornaram-se conhecidos através do renomado missionário presbiteriano afro-americano William Sheppard, tendo ele também formado a primeira coleção de material relacionado aos bakuba, hoje no College Museum at Hampton Institute (cf. Cureau 1982). A arte kuba, então, deve ser relacionada aos fatos que antecederam de perto a partilha da África, e que se

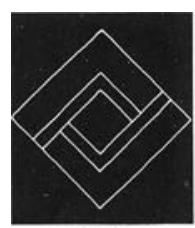

Woot

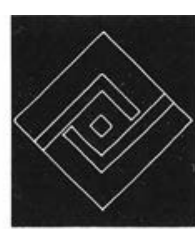

Ikwaak'l iwoot

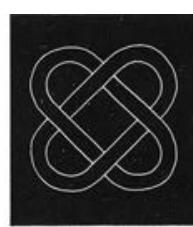

Imbol

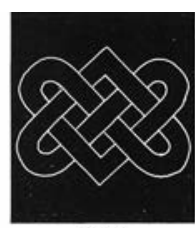

Imbol

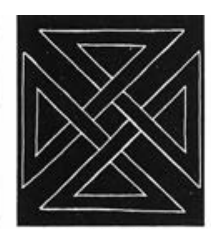

Ikashintaan

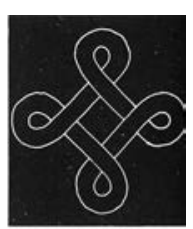

Ibwoobwo
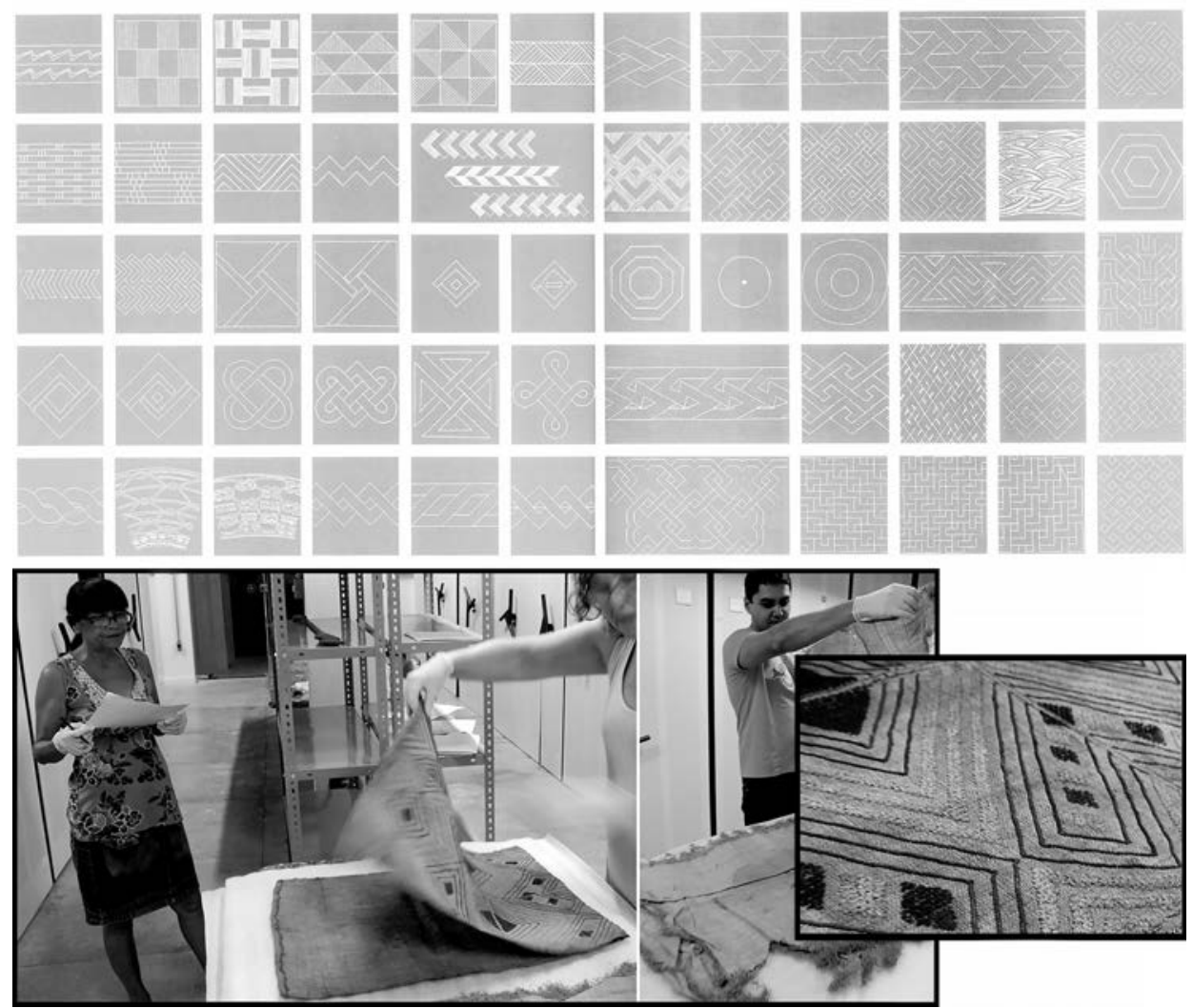

Fig. 9. Como pano de fundo, desenhos do sistema decorativo encontrados na análise da arte real kuba, por Cornet (1982: 160-161), destacando-se a fileira em que se encontram o ibol e sua variante ikashintaan citados no texto. Abaixo, vai um registro do trabalho em conjunto com os técnicos de curadoria Suzana Primo e Fabio Jacob, destacando-se dois tecidos kuba lá conservados (Fotografias da autora e de Fábio Jacob, 2012; direito de uso MPEG/MCTI). 
desdobram na fase mais aguda da escravidão e exploração da borracha no Congo (Hochschild 1999). Seu sistema decorativo poderia, assim, alinhavar a história dos bakuba e de outros povos da África central com a história das ciências, sendo Torday (1910) um dos títulos enviesados sobre essa história.

Na parte superior da Fig. 9, vemos um desenho elementar do sistema decorativo kuba, de grande proximidade com os tusona tshokwe e ngangela. Faz parte dos bwiin, como são chamados genericamente todos os componentes do sistema decorativo kuba, tal como apresentado em Cornet (1982: 160-161, fig. 103).

Trata-se do desenho ibol - um entrelaçamento de linhas recurvado em suas extremidades, formando um todo fechado e comportando curvas com entrelaçados. Constituído de um módulo simples, pode ser mais complexo se for desdobrado por si mesmo e se multiplicar sobre uma só faixa que gera o desenho que se vê no processo final de sua aplicação. Geralmente o desenho ibol complexo se aplica a um cinto cerimonial, e quando simples (dois módulos primordiais entrecruzados) em um pingente de cintura como também em uma espécie de pala ou gola da indumentária real.-

Mas causa interesse o ibol "extrovertido" que, como diz Cornet (1982: 168), "recusa ligações com o exterior”. É um desenho extremamente próximo àquele mais reconhecido dos batshokwe cujas variações foram destacadas na Fig. 8 - um desenho em cruz, portanto, "voltado pra dentro". Segundo ele, esse desenho ibol tem o nome específico de ikashintaan, ou "pata do leão", sendo itaan um nome de origem luba. Pela tradição oral, temos um importante componente dos baluba na formação dos batshokwe.

Mas, não seria o caso de prosseguir com outras correlações a que o tema poderia aludir entre essas sociedades. Ainda que as culturas tshokwe e kuba possam ter um pano de fundo histórico e cultural comum pelo menos desde o século XVI, não há elementos além dos formais para relacionarmos os desenhos de uma e outra sociedade.

Como se lê em Cornet (1982: 157) a respeito do que observou Emil Torday entre os bangwoong (Torday et al. 1910), e ele próprio entre os bashibushoong, o sistema decorativo e os nomes dos desenhos, assim como sua aplicação são diferentes até mesmo entre ramificações do próprio complexo kuba.

Vimos como os protótipos e variantes cruciformes dos desenhos cingelyengelye do batshokwe e ibol dos bakuba podem nos confundir e que sua decodificação depende ora do discernimento da forma básica de que são compostos os padrões em que são inseridos, ora pelo suporte em que são aplicados - sem se considerar aí os condicionantes históricos e contextuais.

Sabemos, em contrapartida, que, desde muito cedo, a presença do signo ortogonal nas expressões visuais das populações da região Congo-Angola chamou a atenção dos europeus, no afã de encontrar ali o tau bíblico, e provavelmente os africanos se beneficiaram da possibilidade de reguardar seus símbolos superficialmente revestidos de uma áurea cristã (cf. Salum 1996: 38-40).

Atualmente, no Brasil, têm sido observados em contexto arqueológico desenhos semelhantes tantos aos protótipos derivados dos elencados por Cornet quanto por Bastin - por ela especialmente em vista das relações históricas comuns entre os batshokwe e outros povos da Lunda assim como com os bakongo, cuja cultura é atestada nas Américas no próprio cotidiano vivido, na língua falada e nos ritos de cultos.

Lucio Menezes Ferreira (2009) observa que objetos de tipos semelhantes achados nos EUA, Caribe e América do Sul são associados a contextos negro-africanos, mas se relacionam mais especificamente com a semelhança das experiências escravas (Singleton 1999 apud Ferreira 2009: 270), estando entre esses achados contas de colar e cachimbos que revelam, antes de mais nada, ações e processos de resistência determinantes na aquisição, produção e uso de artefatos pelos africanos escravizados na diáspora. Um levantamento sistemático da bibliografia básica desses estudos, tal qual surgiu nos EUA, pode ser encontrado em Orser (1994), que estabelece relações entre material arqueológico relativo à escravidão e práticas religiosas de herança africana.

Entre nós, no Brasil, Luis Cláudio Symanski tem disseminado a perspectiva da arqueologia da diáspora nos estudos de cultura material, aprofundando estudos sobre a icono- 
grafia dos viajantes (cf. Symanski 2010), já de antes sustentado pela erudição do conhecimento da etnografia da África aplicado na análise de contextos arqueológicos afro-americanos desde início da década de 1990 (Symanski 2007). Ao menos tempo, ele tem estabelecido parâmetros históricos para interpretar a recorrência do signo cruciforme atribuído aos bakongo - uma cruz encerrada em um círculo - a um desenho da decoração cerâmica em vasilhames oriundos de sítios de Chapada dos Guimarães com datação média iniciando em 1836, período que tem como aquele em que escravos Congo estavam se tornando o grupo africano majoritário na região (Symanski 2007: 21). Observou também agrupamentos de artefatos de uso ritual nos cantos das edificações e sob o solo, associando-os aos minkisi (Symanski 2007: 24 e ss.), tendo como uma de suas referências Flash of Spirits de Robert Farris Thompson, sabidamente referência nos estudos das relações entre espiritualidade e arte entre África e Áméricas (cf. Thompson 2011, já publicado em português no Brasil, sendo sua primeira edição de 1983, em inglês).

Esses achados em contextos escravagistas, quando reportados a formas, desenhos ou grafismos de que tratamos acima, relacionados a culturas da África central, trazem à tona o valor dos estudos de arte africana, que mesmo no tocante aos candomblés, são pouco valorizados nas pesquisas africanistas entre nós.

Sabe-se, porém, que não basta orientar-se pela diáspora do tráfico atlântico para determinar o percurso da África para o Brasil de formas e grafismos, e que a analogia feita entre eles - igualmente quando entre as culturas de que se originaram, ou em que, no continente africano, foram cultivados - deve ser compreendida não apenas por um recorte diacrônico, pelo qual devemos manter a observância dos dados contextuais, mas na consideração da existência de parâmetro ético-estético de grande abrangência entre as partes relacionadas. De certo modo, compreende-se aí a reflexão metodológica que Camilla Agostini desde cedo enuncia (Agostini 1998).

Além de sua contribuição na interpretação da cultura material implicada em formas específicas de construção de identidade a partir da África, as ramificações da arqueologia da es- cravidão e da diáspora têm se tornado fecundas também por permitir a recuperação dos estudos de cultura material da África, por muito tempo reservado aos estudos de arte africana no campo da etnologia africana.

Os estudos sobre grafismos tshokwe e kuba nos remetem ao trabalho de Frans Olbrechts (1959), pioneiro no que respeita à identificação estilística do repertório da cultura material da África acumulada pelos museus desde as expedições que prenunciaram a partilha da África como a expedição germânica do Loango de 1873 em que se destaca Adolf Bastin como um dos grandes coletores. Foi Frans Olbrechts, que, indiscutivelmente, fez da análise morfológica um dos métodos mais utilizados no estudo das artes da África no século XX até pelo menos os anos 1970-1980. Seu trabalho vê-se realçado na metodologia de François Neyt para o estabelecimento de sua tipologia da grande estatuária hemba (Neyt 1977), que, por sua vez, foi adotada para a dos basonge em Salum (1990).

Mas, depois da identificação do "atelier de Buli” por Olbrechts, começaram a surgir estudos de "mãos de artista" da África, determinando autoria mas nem sempre os artistas, muitos dos quais identificados pela sua localidade ou designação familiar. Importantes resultados vieram dos estudos feitos nessa linha sobre a arte dos iorubás (cf., entre outros, Willett e Picton 1967; Abiodun, Drewal e Pemberton 1994). Mas, verdade seja dita, o anonimato sempre interessou ao colecionismo imbricado nesse tipo de estudo, a se considerar a busca desenfreada pela arte africana até décadas recentes, discutida em Schildkrout e Keim (1998). Tudo isso certamente é um todo que permeia os estudos de arte africana associados ao comércio internacional desses objetos e os preços que eles alcançam no mercado desde seus primórdios, desde mesmo o século XIX, como obervamos com relação às armas mais atrás.

Com isso, o trabalho de Marie-Louise Bastin (1961) e Joseph Cornet (1982), como outros dessa tradição de estudos surgidos a partir, em última instância, do MRAC, há de ter contribuído, direta ou indiretamente, com interesses particulares desde pelo menos a instauração da situação colonial. 
É o que se pode depreender da leitura de Bouttiaux (1999), sobre a formação das coleções do Museu de Tervuren e é o que traz Wastiau (2000) com estudos de caso sobre seus bastidores.

Isso não desqualifica absolutamente os trabalhos de Bastin e Cornet aqui trazidos, mas eles também devem ser olhados na especificidade das condições e período em que foram realizados, com as limitações históricas que estudos sobre relação entre forma e conteúdo podem oferecer.

Na publicação que acompanha a exposição Frans Olbrechts 1899-1958: in search of art in Africa realizada pelo Etnografisch Museum da Antuérpia, temos ensaios de estudiosos como o de Constantine Petridis (2001), organizador da obra, em que se apontam alcances e limitações da pesquisa estilística das artes da África, particularmente da África central, revendo conceitos e temas como área cultural e estilo; técnica e identidade do artista; estilo, "tribo" e história.

Concluindo que são raras as tentativas bem sucedidas tomadas nesse sentido, mesmo associando-se a análise morfológica a abordagens contextuais, Petridis nos faz lembrar que, como os trabalhos de arte em si mesmos, "os estilos não se movem no vazio" (Petridis, 2001: 140).

Com isso, e tendo-se a precedência do pensamento de Frans Boas no método de análise morfológica das artes do Congo desenvolvido por Olbrechts, vem-nos o trecho com que Lévi-Strauss termina seu artigo inspirado no desdobramento da representação da arte da costa pacífica do noroeste da América de Boas em seu clássico Primitive Art de 1927:

“(...) mesmo se fosse permitido invocar a difusão, essa difusão não poderia ser de detalhes, de traços independentes viajando cada um por sua conta, desprendendo-se à vontade de uma cultura para vir se agregar a outra, mas de conjuntos orgânicos onde o estilo, as convenções estéticas, a organização social e a vida espiritual estão estruturalmente ligados.(...)" (Lévi-Strauss 1996: 304).

Como se sabe, nesse artigo, Lévi-Strauss identifica analogias entre artes de quatro sociedades diversas das Américas e do Pacífico, destacando-se a dualidade entre o elemento plástico e gráfico nelas presente. Nas palavras do autor, essa dualidade "é ao mesmo tempo uma correlação", e o problema é, então, saber-se em que condições esses elementos são tidos necessariamente em correlação. Refere-se ao que observou no caso de ser o corpo o elemento plástico, e a tatuagem ou pintura corporal, o gráfico: "A decoração, efetivamente, é feita para o rosto, mas, num outro sentido, o rosto é predestinado à decoração (...) é concebida para o rosto, mas o próprio rosto não existe se não por ela. A dualidade é, em definitivo, a do autor e de seu papel, e é a noção de máscara que nos traz a chave" (Lévi-Strauss 1996: 298).

\section{A título de conclusão}

No trabalho atual com coleções em museus, é necessário relativizar o conhecimento sobre características de estilo e tomá-las como referência com precaução. Elas podem ser aplicadas no tratamento técnico das coleções, mas não como fonte de investigação, já que as coleções, sobretudo as africanas, não se colocam mais a serviço do seu principal objetivo, que ficou no passado, ou seja, de tentativa de compreensão das culturas de que provêm.

Seja hoje, como ontem, poderíamos dizer que o significado de certas produções artefatuais e coleções está mais associado ao das instituições e às ideologias sob as quais se tornaram objeto de estudo ou interesse. Diante dos exemplos abordados no texto, é necessário, pois, perguntar-nos, antes, de que "tshokwe" ou "kongo", ou de que "kuba" ou "songye" estamos falando. Sabemos que quase sempre não mais encontraríamos a resposta, e essa pergunta não foi feita, pelo menos nos termos em que hoje se coloca, nem por Bastin e Cornet, nem por Olbrechts, quanto mais pelos que legaram registros iconográficos de época, pelo desenho ou por fotografia. A contextualização do dado etnográfico só pode ser feita no tempo presente da investigação.

Tratamos de correlações entre fontes que se situam em uma discussão epistemológica necessária na descolonização do conhecimento sobre a África, e não é em similaridades formais e analogias entre símbolos que encontramos as 
chaves de que precisamos para interpretação de objetos, formas, grafismos.

No artigo em que Bastin se pergunta se há chaves para distinguir estilos de culturas tão próximas como tshokwe, lwena, songo, ovimbundu e ngangela, ela conclui dizendo: "toda obra tem a marca estilística de uma tradição regional, mas também e sobretudo a de seu criador (...) os ornamentos corporais dependem frequentemente da escolha que fez o escultor entre a rica amplitude do repertório dessa região da África” (Bastin 1971: 17). No repertório que ela levantou, vimos além de elementos cruciformes e curvilíneos, rosáceas, círculos concêntricos, zigue-zagues. Fica a convicção de que nem todo signo ortogonal é uma cruz, assim como nem toda rosácea é um ícone solar como afirmam os especialistas para os bakongo, batshokwe ou ovimbundu. E não é porque a rosácea pode remeter também à arte decorativa do Reino de Benin, de contexto histórico e geográfico completamente diverso, ainda que africano, nem por causa da semelhança do desenho elementar dos bakuba com o ícone cruciforme dos batshokwe. Afinal, este é um legado dos estudos clássicos de arte africana no campo da etnologia africana: alimentar na sua argumentação metodológica a crítica do método comparativo pelo qual devem ser sistematicamente criticados e reavaliados.

Resta dizer uma palavra final sobre o uso da iconografia histórica, pelo qual iniciamos o artigo: qualquer imagem pode se revelar como importante recurso para contextualização de objetos, mas o seu uso afeta a natureza desses objetos, exigindo o estabelecimento de parâmetros para o discernimento entre os limites entre iconografia e imaginário sobre a África. Certamente que contas, armas ou qualquer artefato isolado não se poderiam constituir em fonte de pesquisa por si mesmos, mas, como tentamos situar aqui, eles podem ser fatores através dos quais possa a presença concreta da África no Brasil ser vista mais próxima de seus contornos, desde que consideradas as especificidades da experiência de seus povos dentro e fora do continente.

\section{Agradecimentos}

A François Boulanger, pela partilha de material sobre catalogação de armas em coleções europeias; a Elaine Veloso Hirata, pela amável contribuição feita à penúltima versão; e, a Juliana Ribeiro da Silva pelas boas observações feitas durante todo o processo de redação deste artigo.

SALUM, M.H.L. Un-covering-exiling findings: views over the Africa of diasporas. R. Museu Arq. Etn., São Paulo, n. 22: 195-218, 2012.

Abstract: This article presents considerations on the use of ethnographical iconography in the approach of African material culture from surveys we have been conducting on the ethnological collections of MAE/USP and Museu Paraense Emílio Goeldi-MPEG/MTCI. Such considerations have emerged due to some African objects related to black African contexts of Brazil, but concern especially studies on typical forms and graphisms of the arts of the Bantu speaking societies of Central Africa of the late nineteenth century to the mid-twentieth century. It points to the caution with which this iconography, forms and grafisms should be treated when of its application as source of research.

Keywords: Africa: material culture studies, African Art: Bantu aesthetic, African Art: Iconography, African Art: metallurgy, Brazil: African ethnology collections, Imaginary Africa-Brazil. 


\section{Referências bibliográficas}

ABIODUN, R; DREWAL, H.; PEMBERTON III, J.

1994 The Yoruba Artist: New Theoretical Perspectives on African Arts. Washington: Smithsonian Institution.

AGOSTINI, C.

1998 Resistência cultural e reconstrução de identidades: um olhar sobre a cultura material de escravos do século XIX. Revista de História Regional, 3 (2): 115-137.

AMARAL, R.C.

2000 A coleção etnográfica de cultura religiosa afro-brasileira do Museu de

Arqueologia e Etnologia da Universidade de São Paulo. Revista do Museu de Arqueologia e Etnologia, São Paulo, 10: 255-270.

AUGÉ, M.

1988 Le dieu objet. Paris, Flammarion. (Nouvelle Bibliothèque Scientifique)

AZEVEDO, P.C.; LISSOVSKY, M.

1988 Escravos brasileiros do século XIX na fotografia de Christiano Jr. São Paulo: Ex-Libris.

BALLARINI, $\mathrm{R}$.

2009 La forma perfetta: sulle tracce della moneta tribale africana. Milano: Galleria Africa Curio.

BASTIN, M.-L.

1961 Art décoratif tshokwe. Lisboa: Companhia de Diamantes de Angola.

1971 Y a-t-il des clés pour distinguer les styles tshokwe, lwena, songo, ovimbundu et ngangela? Africa-Tervuren, 17 (1): 5-18.

BLIER, S.P.

1995 African vodun: art, psychology, and power. Chicago: University of Chicago Press.

BOUTTIAUX, A.-M.

1999 Des mises en scène de curiosités aux chefs-d'oeuvre mis em scène. Le Musée royal de l'Afrique à Tervuren: un siècle de collections. Cahiers d'études africaines, 39 (155-156): 595-616.

CARNEIRO DA CUNHA, M.

1983 Arte afro-brasileira. In: Zanini, W. (Coord.) História geral da arte no Brasil. Vol. 2. São Paulo, Instituto Walther Moreira Salles: 973-1033.

CHILDS, S.T.; KILLICK, D.

1993 Indigenous African Metallurgy: Nature and Culture. Annual Review of Anthropology, 22: 317-337.

CORNET, J.A.; NEYT, F.; BASTIN, M.-L.; BASSANI, E.

1997 Réceptacles. Paris: Editions Dapper. (Publication Musée Dapper, 25)
CORNET, J-A

1982 Art royal kuba. Milano: Edizioni Sipiel.

CRÉDIT COMMUNAL

1992 Beauté fatale: armes d'Afrique centrale. Bruxelles: Crédit Communal.

CUREAU, H.G.

1982 William H. Sheppard: Missionary to the Congo, and Collector of African Art. The Journal of Negro History, 67 (4): 340-352.

DAPPER, O.

1989 Description de l'Afrique, 1686. In: Husson, L.; Falgayrettes, C.; Martin, P.M.; Dapper, O. Objets interdits (suivi d'une reproduction partielle de l'ouvrage de Adams Jones Olfert Dapper: Description de l'Afrique, à partir de son édition de 1686). Paris: Fondation Dapper: 89-357.

ELSEN, J. (ED.)

2003 De fer et de fierté: armes blanches d'Afrique noire du Musée Barbier-Mueller. Genève: Musée Barbier-Mueller; Milan: 5 Continents.

FERREIRA, L.M.

2009 Sobre o conceito de arqueologia da diáspora africana. MÉTIS: história \& cultura, 8 (16): 267-275.

FIGUEIREDO, N.; RODRIGUES, I.

1988 O cotidiano e o ritual na análise etnográfica: um estudo de caso: a Coleção Africana do Museu Goeldi. Dédalo, São Paulo, 26: 11-26.

1989 A coleção etnográfica africana do Museu Paraense Emílio Goeldi. Belém: MPEG (Coleção Eduardo Galvão).

FORLACROIX, C.

1970 La photographie au service de l'histoire d'Afrique: presentation des documents photographiques conservés à la phototèque de la Bibliotèque Universitaire d'Abidjan. Cahiers d'Etudes Africaines, 10 (37): $125-43$

GEARY, C.M.

1986 Photographs as Materials for African History Some Methodological Considerations. History in Africa, 13: 89-116.

1988 Images from Bamum: German colonial photography at the court of King Njoya, Cameroon, West Africa, 1902-1915. Washington: National Museum of African Art/Smithsonian Institute Press. 
GONSETH, M.-O.; HAINARD, J.; KAEHR, R.

2002 Musée Cannibale. Neuchâtel: Musée d'Ethnographie.

GRAHAM, S.L.

2012 Ser mina no Rio de Janeiro do século XIX. Afro-Ásia, 45: 25-65.

HERBERT, E.W.

1993 Iron, Gender and Power: rituais de transformação in African Societies. Bloomington; Indianapolis: Indiana University Press.

1994 Beauté Fatale: Armes d'Afrique Centrale. Review by: Eugenia W. Herbert. African Arts, Los Angeles, 27 (1): 89-90+96.

HILBERT, P.P.

1961 Exposição de arte negra [folheto de exposição]. V REUNIÃO DA ASSOCIAC̣ÃO BRASILEIRA DE ANTOPOLOGIA. Belo Horizonte: ABA.

HISTORICAL PHOTOGRAPHS OF AFRICA

1991 African Arts, Los Angeles, 24 (4). (Special Issue)

HOCHSCHILD, A.

1999 O Fantasma do Rei Leopoldo. São Paulo: Companhia das Letras.

HUSSON, L.; FALGAYRETTES, C.; MARTIN, P.M., DAPPER, O.

1989 Objets interdits (suivi d'une reproduction partielle de l'ouvrage de Adams Jones Olfert Dapper: Description de l'Afrique, à partir de son édition de 1686). Paris: Fondation Dapper.

KUBIK, G.

1986 African Graphic Sistems with particular reference to the Benue-Congo or "Bantu" languages zone. Muntu, CICIBA, 4-5: 71135.

LEFEBVRE, L.; DE WAELE, D.

2011 Kilonda: haches des Songye et voisins. Lille: [s/e].

LEFEBVRE, L.

2009 Âmes de formes, formes de lames: Catalogue de l'exposition. Lille: Espace culturel "Terre d'Aventure \& Voyageurs du monde". (Collection Luc Lefebvre)

LÉVI-STRAUSS, C.

1996 O desdobramento da representação nas artes da Ásia e da América. In: Antropologia estrutural. Rio de Janeiro, Tempo Brasileiro: 279-304 (Tempo Universitário, 7)

MUNANGA, $\mathrm{K}$.

2000 Arte afro-brasileira: o que é, afinal? In: Aguilar, N. (Org.) FUNDAÇÃO BIENAL DE SÃO PAULO. In: Mostra do Redescobrimento: arte afro-brasileira. São Paulo,
Associação Brasil 500 Anos Artes Visuais: 98-111.

2004 Introdução. In: Munanga (Org.) História do negro no Brasil: o negro na sociedade brasileira: resistência, participação, contribuição. Brasília, Fundação Cultural Palmares; CNPq: 6-8.

NEYT, F.

1977 La grande statuaire hemba du Zaire. Louvain-la-Neuve: UCL (Publ. d'Histoire de I'Art et d'Archéologie de I'UCL, 12)

OLBRECHTS, F.

1959 Les arts plastiques du Congo Belge. Bruxelles: Erasme.

OLDMAN, W.O.

1903-1907 Catalogue of Ethnographical Specimens. London: W.O. Oldman.

OLHAR SOBRE MACABU.

2012 Disponível em http://olharsobremacabu. blogspot.com.br/2012/03/exposicao-conta-historia-de-conceicao.html.

ORSER JR., C.E.

1994 The Archaeology of African-American Slave Religion in the Antebellum South. Cambridge Archaeological Journal, 4 (1): 33 45.

PETRIDIS, C. (ED.)

2001 Frans M. Olbrechts 1899-1958: In search of Art in Africa. Antwerp: Ethnographic Museum.

REIS, J.J.

2003 Rebelião escrava no Brasil: a história do levante dos malês em 1835. São Paulo: Companhia das Letras.

RIBEIRO JR., A.; SALUM, M.H.L.

2003 Estudo estilístico e iconográfico das esculturas edan do acervo do MAE-USP. Revista do Museu de Arqueologia e Etnologia, São Paulo, (13): 227-258.

RIBEIRO JR., A.

2008 Parafernália das mães-ancestrais: as máscaras gueledé, os edan ogboni e construção do imaginário sobre as "sociedades secretas" africanas no Recôncavo Baiano. Dissertação (Mestrado em Arqueologia) - Museu de Arqueologia e Etnologia, Universidade de São Paulo, São Paulo.

RODRIGUES DE AREIA, M.L.

1985 Les symboles divinatoires: analyse socio-culturelle d'une technique de divination des cokwe de l'Angola. Coimbra: Instituto de Antropologia, Universidade de Coimbra. (Publicações do Centro de Estudos Africanos, 4) 
RODRIGUES DE AREIA, M.L.; KAEHR, R.

1992 Les signes du pouvoir. Neuchâtel: Musée d'Ethnographie.

SALUM, M.H.L.; SOUZA E SILVA, W.

2005-2006 Por que das hastes de ossaim brotam pássaros - até flechas brotam! -, mas não folhas???!!!. Rev. do Museu de Arqueologia e Etnologia, São Paulo, 15-16: 291-320.

SALUM, M.H.L.

1988 Termos classificatórios do objeto de arte africana nas coleções: um problema para os acervos museográficos no Brasil. Dédalo, São Paulo, 26: 43-60.

1990 A grande estatuária songe do Zaire. Dissertação (Mestrado em Antropologia) - Faculdade de Filosofia, Letras e Ciências Humanas da Universidade de São Paulo, São Paulo.

1996 A madeira e seu emprego na arte africana: um exercício de interpretação a partir da estatuária bantu. Tese (Doutorado em Antropologia) - Faculdade de Filosofia, Letras e Ciências Humanas da Universidade de São Paulo, São Paulo.

2004 “Imaginários negros”, negritude e africanidade na arte plástica brasileira. In: Munanga, K. (Org.) História do negro no Brasil: o negro na sociedade brasileira: resistência, participação, contribuição. Brasília, Fundação Cultural Palmares: 337-380.

2008 O homem e sua obra, e, os objetos e os homens: da relação homem-matéria. In: MUSEU, IDENTIDADES E PATRIMÔNIO CULTURAL. Rev. do Museu de Arqueologia e Etnologia. Suplemento 7: 49-61.

2010 Por mais que sejam belas, que dizem simples contas? In: XV CONGRESSO DA SOCIEDADE DE ARQUEOLOGIA BRASILEIRA, 2009. Anais Trabalhos Científicos, Comunicação, Parte II: 69. 76. Disponível em http://www.sabnet. com.br/resources/content/anais 2009 / ANAIS_Comunicacao_2.pdf.

SCHILDKROUT, E.; KEIM, C. (EDS.)

1998 The Scramble for Art in Central Africa. Cambridge: University Press.

SILVA, J.R. DA.

2011 Homens de ferro: os ferreiros da África Central no século XIX. São Paulo: Alameda.

2006 As jóias africanas do acervo do MAE/USP e o problema de classificação. Relatório (Iniciação Científica) - Museu de Arqueologia e
Etnologia da Universidade de São Paulo, São Paulo.

STEINER, C. B.

1994 Africa Art in Transit. Cambridge: Cambridge University Press.

SYMANSKI, L.C.P.

2010 Cerâmica, identidades escravas e crioulização nos engenhos da Chapada dos Guimarães (MT). História Unisinos, 14 (3): 294-310.

2007 O domínio da tática: práticas religiosas de origem africana nos engenhos de Chapada dos Guimarães (MT). Vestígios, Revista Latino-Americana de Arqueologia Histórica, 1(2): 9-36.

THOMPSON, R.F.

2011 Flash of the Spirit: Arte e filosofia africana e afro-americana. São Paulo: Museu Afro Brasil.

TORDAY, E.; JOYCE, T.A.; HARDY, N.H.

1910 Notes ethnographiques sur les peuples communément appelés Bakuba, ainsi que sur les peuplades apparentées, les Bushongo. Vol. 2. Bruxelles: Ministère des colonies: en vente chez Falk fils.

TURNER, T.S

1980 The Social Skin. In: Cherfas, J.; Lewin, R. (Ed.) Not work alone: A cross-cultural view of activities superfluous to survival. London, Temple Smith: 112-140.

VANSCHUYLENBERGH, P.E.; AZIZA, M.Z. (DIR.)

2010 Patrimoine d'Afrique centrale. Archives films: Congo, Rwanda, Burundi, 1912-1960. Tervuren: MRAC.

VELLUT, J.-L. (ED.)

2005 La mémoire du Congo: le temps colonial. Gand: Editions Snoeck; Tervuren: MRAC.

VERSWIJVER, G. (ED.)

1995 Trésors d'Afrique: Musée Tervuren. Tervuren: MRAC.

VIDAL, L.B.

2001 As artes indígenas e seus múltiplos mundos. In: OLHAR O BRASIL. Revista do Patrimônio Histórico e Artístico Nacional, 29: $11-41$.

WASTIAU, B.

2000 ExitCongoMuseum: un essai sur la vie sociale des chefs-d'oeuvre du Musée de Tervuren. Tervuren: MRAC.

WEBSTER, W.D.

1896 Catalogue of Ethnological Specimens, Europe an and Eastern Arms and Armor, prehistoric and other curiosities on sale. Bicester: Oxon. 
Des-En-terrando achados: vistas sobre a África das diásporas.

R. Museu Arq. Etn., São Paulo, n. 22: 195-218, 2012.

\section{WESTERDIJK, $\mathrm{H}$.}

1975 IJzerwerk van Centraal-Afrika. Rotterdam: Museum voor Land- en Volkenkunde; Lochem: De Tijdstroom.

\section{WILLETT, F.; PICTON, J.}

1967 On identification of individual carvers: a study of ancestor shrine carvings frorn Owo, Nigeria. Man, 2 (1): $62-70$. 